\title{
Alternaria Leaf Spot Caused by Alternaria Species: An Emerging Problem on Ornamental Plants in Italy
}

\author{
Slavica Matić, ${ }^{1,2, \dagger}$ Giulia Tabone, ${ }^{1}$ Angelo Garibaldi, ${ }^{1}$ and Maria Lodovica Gullino ${ }^{1,2}$ \\ ${ }^{1}$ AGROINNOVA - Centre of Competence for the Innovation in the Agro-environmental Sector, Università di Torino, 10095 \\ Grugliasco (TO), Italy \\ ${ }^{2}$ Dept. Agricultural, Forestry and Food Sciences (DISAFA), Università di Torino, 10095 Grugliasco (TO), Italy
}

\begin{abstract}
Serious outbreaks of Alternaria leaf spot and plant decay have recently been recorded on several ornamental plants in the Biella Province (Northern Italy). Twenty-two fungal isolates were obtained from Alternaria infected plant tissues from 13 ornamental hosts. All the isolates were identified morphologically as small-spored Alternaria species. Multilocus sequence typing, carried out by means of ITS, rpb2, tefl, endoPG, Alt a 1, and OPA10-2, assigned 19 isolates as Alternaria alternata, two isolates as belonging to the Alternaria arborescens species complex, and one isolate as an unknown Alternaria sp. Haplotype analyses of ornamental and reference A. alternata isolates from 12 countries identified 14 OPA10-2 and 11 endoPG haplotypes showing a relatively high haplotype diversity. A lack of host specialization or geographic distribution was observed. The host range of the studied

A. alternata isolates expanded in cross-pathogenicity assays, and more aggressiveness was frequently observed on the experimental plants than on the host plants from which the fungal isolates were originally isolated. High disease severity, population expansion, intraspecies diversity, and increased range of experimental hosts were seen in the emergence of Alternaria disease on ornamentals. More epidemiological and molecular studies should be performed to better understand these diseases, taking into consideration factors such as seed transmission and ongoing climate changes.

Keywords: Alternaria leaf spot, ornamental species, molecular characterization, multi-locus sequence typing, haplotype analyses, pathogenicity assays
\end{abstract}

Alternaria is a large, ubiquitous dictyosporic genus belonging to the phylum Ascomycetes and order Hyphomycetes (Thomma 2003). Alternaria species range from saprophytes to endophytes and may also be pathogens of plants and animals. These fungal species may infect different group of plants such as vegetables, cereals, and fruit trees during production and storage (Freire et al. 2017; Pavón et al. 2015). The species belonging to the genus Alternaria, Alternaria alternata (Fr.:Fr.) Keissl in particular, pose a serious risk of infection to horticultural crops throughout the world due to pathogen spread by the market globalization of the seeds, long-distance airborne-dispersal of spores, and the effects of climate change (De Saeger and Logrieco 2017; Gilardi et al. 2018; Gullino et al. 2019; O'Hara et al. 2016; Pugliese et al. 2012).

The taxonomy of Alternaria has recently undergone a phylogenetic modification on the basis of nine-locus type sequencing (Woudenberg et al. 2015). This study has grouped around 50 different Alternaria morphological species into the Alternaria sect. Alternaria is now composed of only 11 phylogenetic species (including $A$. alternata) and one additional species complex (the $A$. arborescens species complex). However, these species share a high genome identity of 97 to $98 \%$ (Woudenberg et al. 2015). A. alternata has a genome composed of 10 autosomes, and some of its strains contain one or two additional 'conditionally dispensable chromosomes,'

${ }^{\dagger}$ Corresponding author: S. Matić; slavica.matic@unito.it

Funding: The study was funded through the 'Development and application of phytopathological diagnostic techniques applied in agrifood sector' project funded by the University of Torino.

*The $\boldsymbol{e}$-Xtra logo stands for "electronic extra" and indicates that two supplementary figures and supplementary tables are published online.

The author(s) declare no conflict of interest.

Accepted for publication 9 March 2020.

C 2020 The American Phytopathological Society which are associated with host-specific pathogenicity, but not with any reproduction ability (Ushijima and Yamamoto 2019). A phylogenetic context of recently sequenced Alternaria genomes indicated that both mating type idiomorphs exist in the A. alternata and A. arborescens species complex, and that gene flow has occurred since the establishment of the A. alternata and A. arborescens lineages (Armitage et al. 2020; Woudenberg et al. 2015).

Alternaria leaf spot disease has appeared in Northern Italy over this decade on various new vegetable hosts, such as cabbage, spinach, chili pepper, basil, and wild and cultivated rocket (Garibaldi et al. 2011, 2019c; Gilardi et al. 2019; Gullino et al. 2014). Alternaria diseases are mainly caused by A. alternata, and in some cases by $A$. arborescens species complex and A. japonica (Gilardi et al. 2018; Gullino et al. 2019). At about the same time, leaf spots began to develop on ornamental and medicinal plants in Northern Italy: the first noted on orange coneflower (Rudbeckia fulgida) was caused by Alternaria sp. (Garibaldi et al. 2015), and then spots seen on peppermint (Mentha $\times$ piperita L.), pineapple sage (Salvia elegans Vahl.), and purple coneflower (Echinacea purpurea L.) were found to be caused by A. alternata (Garibaldi et al. 2018a, b, c). Recently, A. alternata has appeared on creeping bellflower (Campanula rapunculoides L.), fruit-scented sage (Salvia dorisiana Stand1.), common coleus (Plectranthus scutellarioides (L.) R. Br.), purple lotus (Ceratostigma willmottianum Stapf.), common foxglove (Digitalis purpurea L.), and hollyhock (Alcea rosea L.) (Garibaldi et al. 2019a, b, d, e, 2020b, c). Another Alternaria leaf spot disease has been found to be caused by the A. arborescens species complex on Michaelmas daisy (Symphyotrichum novi-belgii) (Garibaldi et al. 2020a).

The necrotrophic behavior of A. alternata is crucial for the pathogenesis and progress of brown spot disease on fruits of citrus trees, due to the production of host-selective toxins (Chung 2012). The necrotrophic activities of A. alternata have also been observed on leafy vegetables, and recently on ornamental species, during the development of Alternaria leaf spot disease. Tiny, circular, brown leaf spots appear as the initial symptoms and they progressively become larger and form patches between the leaf veins; this is followed by sectorial or complete leaf necrosis. Plant 
Table 1. List of Alternaria spp. isolates used for the molecular characterization

\begin{tabular}{|c|c|c|c|c|c|c|c|c|c|}
\hline \multirow[b]{2}{*}{ Isolate $^{\mathbf{a}}$} & \multirow[b]{2}{*}{ Origin $^{a}$} & \multirow[b]{2}{*}{ Host $^{\mathbf{a}}$} & \multicolumn{6}{|c|}{ GenBank accession number ${ }^{b}$} & \multirow[b]{2}{*}{ Species } \\
\hline & & & Alt a 1 & endoPG & ITS & OPA10-2 & $r p b 2$ & tef1 & \\
\hline DB17GIU22 & Italy & Salvia elegans (pineapple sage) & MN615845 & MN627291 & MN565909 & MN566326 & MN566288 & MN627317 & A. alternata \\
\hline 456 & Italy & Salvia elegans (pineapple sage) & MN615846 & MN627292 & MN565910 & MN566327 & MN566289 & MN627318 & A. arborescens \\
\hline IT44 & Italy & $\begin{array}{l}\text { Echinacea purpurea } \\
\quad \text { (purple coneflower) }\end{array}$ & MG598796 & MG598798 & MG182428 & MN566328 & MN566290 & MN627319 & A. alternata \\
\hline IT44-2 & Italy & $\begin{array}{l}\text { Echinacea purpurea } \\
\quad \text { (purple coneflower) }\end{array}$ & MG598797 & MG598799 & MG598794 & MN566329 & MN566291 & MN627320 & A. alternata \\
\hline DB18MAG21 & Italy & Salvia dorisiana (fruit-scented sage) & MN615847 & MN627293 & MH536113 & MN566330 & MN566292 & MN627321 & A. alternata \\
\hline DB18MAG21R & Italy & Salvia dorisiana (fruit-scented sage) & MN615848 & MN627294 & MN565911 & MN566331 & MN566293 & MN627322 & A. alternata \\
\hline $6-518$ & Italy & Salvia dorisiana (fruit-scented sage) & MN615849 & MN627295 & MH536112 & MN566332 & MN566294 & MN627323 & Alternaria sp. \\
\hline IT22 & Italy & $\begin{array}{l}\text { Campanula rapunculoides } \\
\text { (creeping bellflower) }\end{array}$ & MN615850 & MN627296 & MH560609 & MN566333 & MN566295 & MN627324 & A. alternata \\
\hline IT22R & Italy & $\begin{array}{l}\text { Campanula rapunculoides } \\
\text { (creeping bellflower) }\end{array}$ & MN615851 & MN627297 & MN565912 & MN566334 & MN566296 & MN627325 & A. alternata \\
\hline 18 & Italy & Digitalis purpurea (common foxglove) & MN615852 & MN627298 & MK185236 & MN566335 & MN566297 & MN627326 & A. alternata \\
\hline 18R & Italy & Digitalis purpurea (common foxglove) & MN615853 & MN627299 & MN565913 & MN566336 & MN566298 & MN627327 & A. alternata \\
\hline $61-4$ & Italy & Ceratostigma willmottianum (purple lotus) & MN615854 & MK558219 & MK204576 & MN566337 & MN566299 & MN627328 & A. alternata \\
\hline REIS 68 & Italy & Ceratostigma willmottianum (purple lotus) & MN615855 & MK558220 & MN565914 & MN566338 & MN566300 & MN627329 & A. alternata \\
\hline 64-31R & Italy & Coreopsis lanceolata (calliopsis) & MN615856 & MN627300 & MN565915 & MN566339 & MN566301 & MN627330 & A. alternata \\
\hline 64-3 & Italy & Coreopsis lanceolata (calliopsis) & MN615857 & MN627301 & MN565916 & MN566340 & MN566302 & MN627331 & A. alternata \\
\hline DB18MAG10 & Italy & $\begin{array}{l}\text { Plectranthus scutellarioides } \\
\text { (common coleus) }\end{array}$ & MN153446 & MN153445 & MH521954 & MN566341 & MN566303 & MN627332 & A. alternata \\
\hline DB18MAG10R & Italy & $\begin{array}{l}\text { Plectranthus scutellarioides } \\
\text { (common coleus) }\end{array}$ & MN153448 & MN153447 & MN565917 & MN566342 & MN566304 & MN627333 & A. alternata \\
\hline 19-11 & Italy & $\begin{array}{l}\text { Campanula trachelium } \\
\text { (nettle-leaved bellflower) }\end{array}$ & MN184998 & MN184997 & MN181428 & MN185000 & MN184999 & MN627334 & A. alternata \\
\hline 19-10 & Italy & $\begin{array}{l}\text { Symphyotrichum novi-belgii } \\
\text { (Michaelmas daisy) }\end{array}$ & MN185002 & MN185001 & MN183754 & MN185004 & MN185003 & MN627335 & A. arborescens \\
\hline 19-24 & Italy & Alcea rosea (hollyhock) & MN615858 & MN258023 & MN249628 & MN258025 & MN258022 & MN258024 & A. alternata \\
\hline 19-38 & Italy & Rudbeckia fulgida (orange coneflower) & MN615859 & MN627302 & MN565918 & MN566343 & MN566305 & MN627336 & A. alternata \\
\hline IT61 & Italy & Mentha $\times$ piperita $($ peppermint $)$ & MN615860 & MN627303 & MF997592 & MN566344 & MN566306 & MN627337 & A. alternata \\
\hline Orig_IT1 & Italy & Origanum vulgare (oregano) & MN615861 & MN627304 & MN565919 & MN566345 & MN566307 & MN627338 & A. alternata \\
\hline cav2_10 & Italy & Brassica oleracea var. botrytis (cauliflower) & MN615862 & MN627305 & МH936379 & MN566346 & MN566308 & MN627339 & A. alternata \\
\hline cav4_10 & Italy & Brassica oleracea var. botrytis (cauliflower) & MN615863 & MN627306 & MH936381 & MN566347 & MN566309 & MN627340 & A. alternata \\
\hline cav6_10 & Italy & Brassica oleracea var. capitata (cabbage) & MN615864 & MN627307 & MH936383 & MN566348 & MN566310 & MN627341 & A. alternata \\
\hline cav7_10 & Italy & Brassica oleracea var. capitata (cabbage) & MN615865 & MK140912 & MH936384 & MN566349 & MN566311 & MN627342 & A. alternata \\
\hline cav9_10 & Italy & Brassica oleracea var. botrytis (cauliflower) & MN615866 & MK140913 & MH936385 & MN566350 & MN566312 & MN627343 & A. alternata \\
\hline cav15_10 & Italy & Brassica oleracea var. capitata (cabbage) & MN615867 & MK140915 & MH936387 & MN566351 & MN566313 & MN627344 & A. alternata \\
\hline ruc3_10 & Italy & Diplotaxis tenuifolia (wild rocket) & $M N 615868$ & MN627308 & MH936389 & MN566352 & MN566314 & MN627345 & A. alternata \\
\hline ruc7_10 & Italy & Diplotaxis tenuifolia (wild rocket) & MN615869 & MN627309 & MH936392 & MN566353 & MN566315 & MN627346 & A. arborescens \\
\hline rucPMP4 & Italy & Eruca sativa (cultivated rocket) & $M N 615870$ & MN627310 & MH936399 & MN566354 & MN566316 & MN627347 & A. arborescens \\
\hline rucPMP12 & Italy & Eruca sativa (cultivated rocket) & MN615871 & MN627311 & MH936401 & MN566355 & MN566317 & MN627348 & A. alternata \\
\hline rucPMP19 & & Eruca & MN6158 & MN627312 & MH936402 & MN566356 & 66318 & MN627349 & A. alternata \\
\hline bas6_10 & Italy & Ocimum basilicum (basil) & MN615873 & MF070306 & MH936407 & MF070474 & MN566319 & MF070342 & A. alternata \\
\hline basBIO_10 & Italy & Ocimum basilicum (basil) & MN615874 & MN627313 & MH936409 & MN566357 & MN566320 & MN627350 & Alternaria sp. \\
\hline basBIO_11 & Italy & Ocimum basilicum (basil) & MN615875 & MN627314 & МH936410 & MN566358 & MN566321 & MN627351 & A. alternata \\
\hline bas18_1BA & Italy & Ocimum basilicum (basil) & $M N 615876$ & MN627315 & MH936412 & MN566359 & MN566322 & MN627352 & A. alternata \\
\hline bas_G1 & Italy & Ocimum basilicum (basil) & MN615877 & MF070307 & MH936408 & MF070475 & MN566323 & MF070343 & A. arborescens \\
\hline AltSpin2-18 & Italy & Spinacia oleracea (spinach) & $M N 615878$ & MK085978 & MK078634 & MN566360 & MN566324 & MN627353 & A. alternata \\
\hline $3-18$ & Italy & Capsicum frutescens (chili pepper) & MN615879 & MN627316 & МH920250 & MN566361 & MN566325 & MN627354 & A. alternata \\
\hline CBS_117130 & taly & Arbutus unedo (strawberry tree) & KP123902 & KP124055 & KP124354 & KP124665 & KP124822 & KP125130 & A. alternata \\
\hline CBS_117143 & Italy & Capsicum annuum (pepper) & KP123903 & KP124056 & KP124355 & KP124666 & KP124823 & KP125131 & A. alternata \\
\hline CBS_63997 & Greece & Helianthus annuus (sunflower) & KP123876 & KP124028 & KP124327 & KP124635 & KP124795 & KP125103 & A. alternata \\
\hline CBS_82668 & Germany & Lolium sp. & KP123860 & KP124007 & KP124307 & - & KP124776 & KP125083 & A. alternata \\
\hline EGS_34015 & UK & Dianthus sp. & AY563302 & KP124026 & AF347032 & KP124633 & KC584435 & KC584693 & A. alternata \\
\hline CBS_11744 & Denmark & Godetia sp. & & & & & 772 & 079 & A. alternata \\
\hline CBS_124281 & Denmark & Triticum sp. & KP123961 & KP124118 & KP124414 & KP124728 & KP124883 & KP125192 & A. arborescens \\
\hline CBS_124282 & Denmark & Hordeum vulgare (barley & KP123962 & KP124119 & KP124415 & KP124729 & KP124884 & KP125193 & A. arborescens \\
\hline CBS_124274 & Denmark & Prunus sp. & KP123960 & KP124117 & KP124413 & KP124727 & - & KP125191 & A. arborescens \\
\hline CBS_124278 & Denmark & Prunus sp. & KP123922 & KP124078 & KP124374 & KP124687 & KP124844 & KP125152 & A. alternata \\
\hline CBS_19586 & Canada & Euphorbia esula (leafy spurge) & JQ646398 & KP124017 & KP124317 & KP124624 & KP124785 & KP125093 & A. alternata \\
\hline CBS_127672 & U.S.A. & $\begin{array}{l}\text { Astragalus bisulcatus } \\
\quad \text { (twogrooved milkvetch) }\end{array}$ & KP123930 & KP124086 & KP124382 & KP124695 & KP124852 & KP125160 & A. alternata \\
\hline CBS_62083 & S.A. & Nicotiana tabacum (tobacc & & KP124015 & KP124315 & & KP124783 & & A. alternata \\
\hline CBS_119408 & J.S.A. & Euphorbia esula (leafy spurge) & JQ646410 & KP124064 & KP124362 & KP124673 & KP124830 & KP125138 & A. alternata \\
\hline CBS_109730 & U.S.A. & Solanum lycopersicum (tomato) & & KP124103 & KP124399 & KP124713 & KP124869 & KP125177 & A. arborescens \\
\hline CBS_17452 & U.S.A. & Anemone occidentalis (pasqueflower) & KP123856 & KP124003 & KC584228 & KP124611 & DQ677964 & KC584704 & A. alternata \\
\hline CBS_44786 & Morocco & Malva sp. & JQ646397 & KP124018 & KP124318 & KP124625 & KP124786 & KP125094 & A. alternata \\
\hline CBS_91197 & India & Artemisia brevifolia (Santonin plant) & KP123875 & KP124027 & KP124326 & KP124634 & KP124794 & KP125102 & A. alternata \\
\hline CBS_96695 & India & Solanum lycopersicum (tomato) & KP123873 & KP124024 & KP124324 & KP124630 & KP124792 & KP125100 & A. alternata \\
\hline CBS_96595 & India & Triticum sp. & KP123872 & KP124023 & KP124323 & KP124629 & KP124791 & KP125099 & A. alternata \\
\hline EGS_34016 & India & Arachis hypogaea (peanut) & AY563301 & JQ811978 & AF347031 & KP124663 & KC584375 & KC584634 & A. alternata \\
\hline CBS_121348 & China & Platycodon grandiflorus (balloon flower) & KP123915 & KP124070 & KP124367 & KP124679 & KP124836 & KP125144 & A. alternata \\
\hline CBS_119544 & $\begin{array}{l}\text { New } \\
\text { Zeals }\end{array}$ & Avena sativa (oat) & KP123955 & KP124112 & KP124408 & KP124722 & KP124878 & KP125186 & A. arborescens \\
\hline CBS_11341 & Unknown & Schizanthus sp. & KP123943 & KP124099 & KP124395 & KP124708 & KP124865 & KP125173 & A. arborescens \\
\hline CBS_10330 & Unknown & Solanum lycopersicum (tomato) & KP123991 & KP124151 & KP124445 & KP124762 & KP124915 & KP125224 & A. tomato \\
\hline
\end{tabular}

a Twenty-two fungal isolates characterized in this study are indicated by bold, as well as their origins and hosts.

${ }^{\mathrm{b}}$ GenBank accession numbers obtained in this study are indicated by bold and italics. Other accession numbers are from previously published studies: Garibaldi et al. (2018b, c, 2019a, b, c, d, e, 2020a, b, c); Gilardi et al. (2019); Siciliano et al. (2018); and Woudenberg et al. (2015). 
decay with defoliation can be observed at the advanced disease stage, occasionally leading to the death of the plant. Alternaria species overwinter as spores or mycelium on infected crop debris, weeds, or on or in seeds (Laemmlen 2001). The spores are airborne and dispersed long distances; the peak of the spore season occurs during the middle of summer in central, northern Europe
(Skjøth et al. 2016). Alternaria species may also be transmitted by seeds: this transmission has been facilitated in particular by the recent globalization of the seed market (Gullino et al. 2014). Seed-transmission has been reported in both leafy vegetables and ornamental plants (Gilardi et al. 2013; Parisi et al. 2018; Wu et al. 2006).

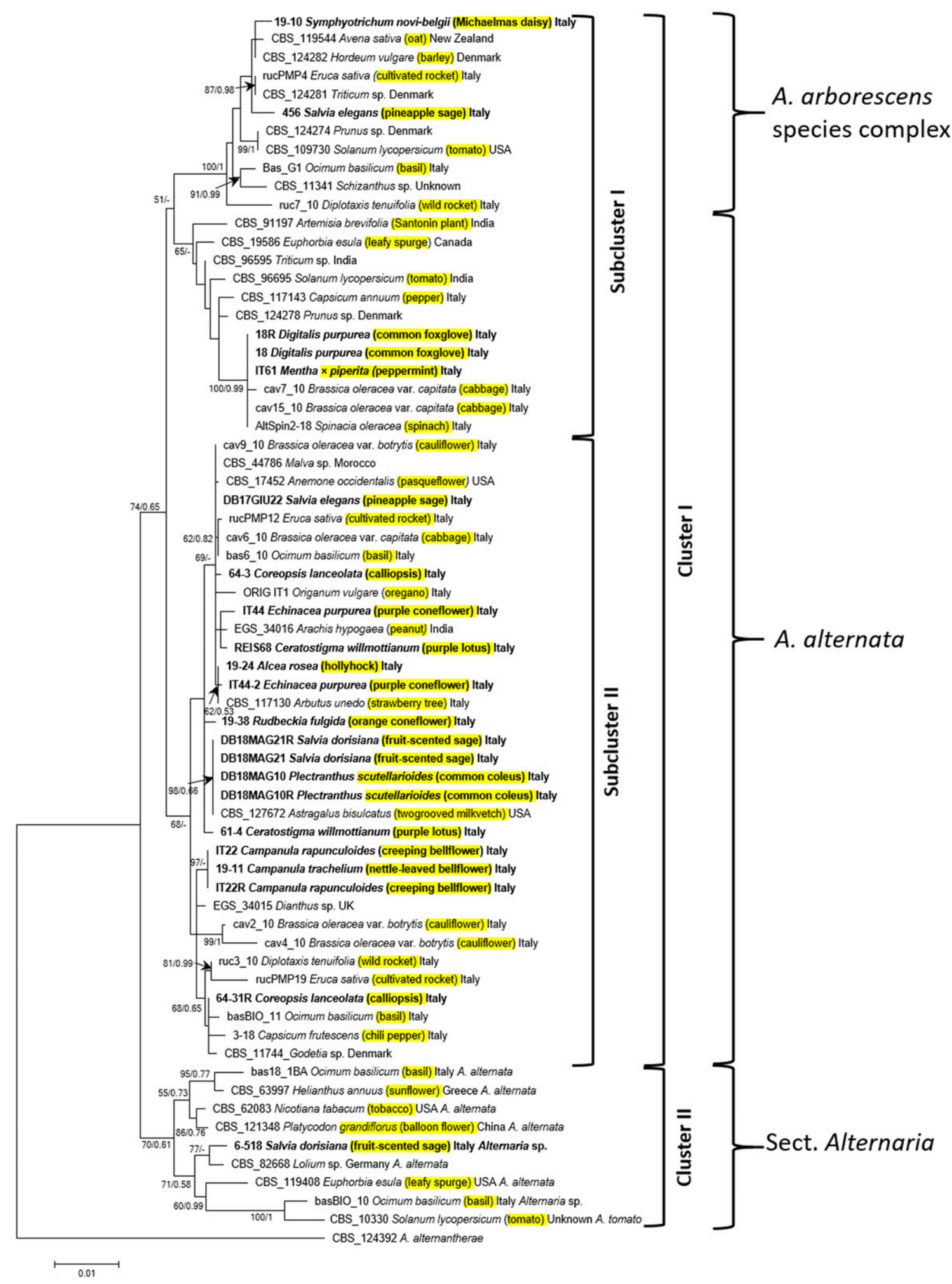

Fig. 1. Phylogram based on ITS, rpb2, endoPG, Alt a 1, tef1, and OPA10-2 sequences of 67 Alternaria isolates. The phylogenetic tree was generated using a maximum likelihood analysis. The studied Alternaria isolates from ornamental hosts are shown in bold. Reference isolates of Alternaria alternata, Alternaria arborescens species complex, and Alternaria tomato from various plant hosts and geographic locations are included in the analyses (Woudenberg et al. 2015). The strain CBS 124392 of Alternaria alternantherae was used as outgroup. Bootstrap values of less than $50 \%$ are not presented. Bayesian posterior probability values obtained by Bayesian analyses are indicated at the nodes next to the bootstrap support values. The name, host affiliation, and geographic origin of the isolates are shown in the figure. 
Table 2. List of individual haplotypes identified for Alternaria alternata isolates used in this study and reference A. alternata isolates from different geographic, host, and isolation origins ${ }^{\mathrm{a}}$

\begin{tabular}{|c|c|c|c|c|c|c|}
\hline \multirow[b]{2}{*}{ No. } & \multirow[b]{2}{*}{ Isolate } & \multirow[b]{2}{*}{ Host/Matrix } & \multirow[b]{2}{*}{ Country } & \multirow[b]{2}{*}{ Isolation origin } & \multicolumn{2}{|c|}{ Haplotype } \\
\hline & & & & & endoPG & OPA10-2 \\
\hline 1 & CBS_88095 & Fragaria vesca (wild strawberry) & Belgium & - & 5 & 13 \\
\hline 2 & Orig_IT1 & Origanum vulgare (oregano) & Italy & Leaf & 6 & 1 \\
\hline 3 & cav4_10 & Brassica oleracea var. botrytis (cauliflower) & Italy & Leaf & 6 & 2 \\
\hline 4 & $61-4$ & Ceratostigma willmottianum (purple lotus) & Italy & Leaf & 2 & 1 \\
\hline 5 & CBS_121336 & Allium sp. & U.S.A. & Leaf & 2 & 10 \\
\hline 6 & ruc3_10 & Diplotaxis tenuifolia (wild rocket) & Italy & Leaf & 3 & 4 \\
\hline 7 & rucPMP19 & Eruca sativa (cultivated rocket) & Italy & Seed & 4 & 4 \\
\hline 8 & DB17GIU22 & Salvia elegans (pineapple sage) & Italy & Leaf & 1 & 1 \\
\hline 9 & 456 & Salvia elegans (pineapple sage) & Italy & Leaf & 1 & 1 \\
\hline 10 & DB18MAG22 & Salvia dorisiana (fruit-scented sage) & Italy & Leaf & 1 & 1 \\
\hline 11 & DB18MAG22R & Salvia dorisiana (fruit-scented sage) & Italy & Leaf & 1 & 1 \\
\hline 12 & IT44-2 & Echinacea purpurea (purple coneflower) & Italy & Leaf & 1 & 1 \\
\hline 13 & 18 & Digitalis purpurea (common foxglove) & Italy & Leaf & 1 & 13 \\
\hline 14 & 18R & Digitalis purpurea (common foxglove) & Italy & Leaf & 1 & 13 \\
\hline 15 & 64-31R & Coreopsis lanceolata (calliopsis) & Italy & Leaf & 1 & 2 \\
\hline 16 & 64-3 & Coreopsis lanceolata (calliopsis) & Italy & Leaf & 1 & 1 \\
\hline 17 & DB18MAG10 & Plectranthus scutellarioides (common coleus) & Italy & Leaf & 1 & 1 \\
\hline 18 & DB18MAG10R & Plectranthus scutellarioides (common coleus) & Italy & Leaf & 1 & 1 \\
\hline 19 & 19-11 & Campanula trachelium (nettle-leaved belfflower) & Italy & Leaf & 1 & 2 \\
\hline 20 & IT22 & Campanula rapunculoides (creeping bellflower) & Italy & Leaf & 1 & 2 \\
\hline 21 & IT22R & Campanula rapunculoides (creeping bellflower) & Italy & Leaf & 1 & 2 \\
\hline 22 & 19-24 & Alcea rosea (hollyhock) & Italy & Leaf & 1 & 1 \\
\hline 23 & IT61 & Mentha $\times$ piperita $($ peppermint) & Italy & Leaf & 1 & 13 \\
\hline 24 & cav2_10 & Brassica oleracea var. botrytis (cauliflower) & Italy & Leaf & 1 & 2 \\
\hline 25 & cav6_10 & Brassica oleracea var. capitata (cabbage) & Italy & Leaf & 1 & 13 \\
\hline 26 & cav7_10 & Brassica oleracea var. capitata (cabbage) & Italy & Leaf & 1 & 13 \\
\hline 27 & cav9_10 & Brassica oleracea var. botrytis (cauliflower) & Italy & Leaf & 1 & 1 \\
\hline 28 & cav15_10 & Brassica oleracea var. capitata (cabbage) & Italy & Leaf & 1 & 13 \\
\hline 29 & rucPMP12 & Eruca sativa (cultivated rocket) & Italy & Seed & 1 & 5 \\
\hline 30 & bas6_10 & Ocimum basilicum (basil) & Italy & Leaf & 1 & 1 \\
\hline 31 & basBIO_11 & Ocimum basilicum (basil) & Italy & Seed & 1 & 2 \\
\hline 32 & AltSpin2-18 & Spinacia oleracea $($ spinach) & Italy & Leaf & 1 & 13 \\
\hline 33 & CBS_117130 & Arbutus unedo (strawberry tree) & Italy & - & 1 & 1 \\
\hline 34 & CBS 175_80 & Unknown & Italy & - & 1 & 13 \\
\hline 35 & CBS 120829 & Punica granatum (pomegranate) & Greece & Fruit & 1 & 2 \\
\hline 36 & CBS_63997 & Helianthus аппииs (sunflower) & Greece & - & 1 & 1 \\
\hline 37 & CBS 119115 & Prunus sp. & Greece & Leaf & 1 & 2 \\
\hline 38 & EGS_34015 & Dianthus sp. & U.K. & - & 1 & 4 \\
\hline 39 & CBS_124277 & Prunus sp. & Denmark & Fruit & 1 & 1 \\
\hline 40 & CBS_11744 & Godetia sp. & Denmark & - & 1 & 3 \\
\hline 41 & CBS_82668 & Lolium sp. & Germany & Seed & 1 & 1 \\
\hline 42 & CBS_116749 & Unknown & Netherlands & - & 1 & 13 \\
\hline 43 & CBS_127672 & Astragalus bisulcatus (twogrooved milkvetch) & U.S.A. & - & 1 & 1 \\
\hline 44 & CBS_17452 & Anemone_occidentalis (pasqueflower) & U.S.A. & - & 1 & 1 \\
\hline 45 & CBS_121544 & Cucumis sativus (cucumber) & U.S.A. & Leaf & 1 & 1 \\
\hline 46 & CBS_118811 & Brassica oleracea & U.S.A. & - & 1 & 7 \\
\hline 47 & CBS_44786 & Malva sp. & Morocco & - & 1 & 1 \\
\hline 48 & CBS 121492 & Cucumis melo (melon) & China & Leaf & 1 & 1 \\
\hline 49 & CBS_61272 & Senecio cineraria (Dusty Miller) & Germany & Leef & 7 & 1 \\
\hline 50 & REIS 68 & Ceratostigma willmottianum (purple lotus) & Italy & Leaf & 8 & 1 \\
\hline 51 & bas18_1BA & Ocimum basilicum (basil) & Italy & Seed & 8 & 1 \\
\hline 52 & CBS 795_72 & Plantago Aristida (bottlebrush plantain) & U.S.A. & - & 8 & 13 \\
\hline 53 & CBS_118812 & Daucus carota (carrot) & U.S.A. & - & 8 & 11 \\
\hline 54 & CBS_19586 & Euphorbia esula (leafy spurge) & Canada & - & 8 & 8 \\
\hline 55 & CBS_96695 & Solanum lycopersicum (tomato) & India & - & 8 & 12 \\
\hline 56 & CBS_96595 & Triticum sp. & India & - & 8 & 9 \\
\hline 57 & CBS_115152 & Psychotria serpens (creeping psychotria) & China & Fruit & 8 & 12 \\
\hline 58 & CBS_121348 & Platycodon grandiflorus (balloon flower) & China & - & 9 & 4 \\
\hline 59 & CBS 121456 & Sanguisorba officinalis (great burnet) & China & - & 9 & 1 \\
\hline 60 & CBS_62083 & Nicotiana tabacum (tobacco) & U.S.A. & - & 9 & 4 \\
\hline 61 & CBS_118814 & Solanum lycopersicum (tomato) & U.S.A. & - & 9 & 4 \\
\hline 62 & CBS 119408 & Euphorbia esula (leafy spurge) & U.S.A. & - & 9 & 11 \\
\hline 63 & EGS_34016 & Arachis hypogaea (peanut) & India & - & 10 & 1 \\
\hline \multirow[t]{2}{*}{64} & CBS_91197 & Artemisia brevifolia (Santonin plant) & India & - & 10 & 6 \\
\hline & & & & & \multicolumn{2}{|c|}{ (Continued on next page) } \\
\hline
\end{tabular}

${ }^{\text {a }}$ Fungal isolates characterized in this study are indicated by bold, as well as their host, country, and isolation origin. 
Table 2. (Continued from previous page)

\begin{tabular}{|c|c|c|c|c|c|c|}
\hline \multirow[b]{2}{*}{ No. } & \multirow[b]{2}{*}{ Isolate } & \multirow[b]{2}{*}{ Host/Matrix } & \multirow[b]{2}{*}{ Country } & \multirow[b]{2}{*}{ Isolation origin } & \multicolumn{2}{|c|}{ Haplotype } \\
\hline & & & & & endoPG & OPA10-2 \\
\hline 65 & CBS_117143 & Capsicum аппиит (pepper) & Italy & Fruit & 10 & 14 \\
\hline 66 & IT44 & Echinacea purpurea (purple coneflower) & Italy & Leaf & 11 & 1 \\
\hline 67 & 3_18 & Capsicum frutescens (chili pepper) & Italy & Leaf & 11 & 2 \\
\hline 68 & CBS_124278 & Prunus sp. & Denmark & Fruit & 11 & 13 \\
\hline
\end{tabular}

Several outbreaks of Alternaria leaf spot disease caused by Alternaria spp. on new ornamental, medicinal and aromatic plants have been recorded lately in various world regions: Europe (Italy, Greece, Serbia), North America (the U.S.A., Canada), South America (Brazil, Uruguay, Mexico), Africa (South Africa, Algeria), Asia (China, South Korea, India, Iraq, Iran, Pakistan), and Australia (Farr and Rossman 2020). In Italy, in addition to the emergence of Alternaria leaf spot diseases on horticultural hosts, isolates of Alternaria that are resistant to some of the fungicides commonly used for its control have also been documented (Matić et al. 2019). This situation requires in-depth studies on the characterization of new Alternaria isolates and the epidemiology of new Alternaria leaf spot diseases.

The objective of this study has been to characterize the causal agents of the emerging leaf-spot diseases on ornamental hosts. For this purpose, 22 Alternaria isolates, obtained from 13 different ornamental hosts, were subjected to molecular characterization by means of multilocus sequence typing. Intraspecies diversity was also estimated by means of haplotype analyses. Single pathogenicity and cross-inoculation tests were performed to evaluate disease severity and to determine the host range under experimental conditions.

\section{Materials and Methods}

Isolate collection. Twenty-two fungal isolates were obtained from affected leaf tissues of ornamental plant species, mainly during 2017 to 2019 , in a private $5,000 \mathrm{~m}^{2}$ garden in Biella Province (Northern Italy). Thirteen ornamental plant species infected by these leaf spot diseases were sampled: purple lotus (C. willmottianum), pineapple sage ( $S$. elegans), fruit-scented sage ( $S$. dorisiana), purple coneflower (E. purpurea), common foxglove (D. purpurea), creeping bellflower (C. rapunculoides), nettle-leaved bellflower (C. trachelium), common coleus ( $P$. scutellarioides), hollyhock (Alcea rosea), Michaelmas daisy (S. novi-belgii), orange coneflower (R. fulgida), peppermint (Mentha $\times$ piperita), and calliopsis (Coreopsis lanceolata) (Table 1). Four reference strains of A. alternata and A. arborescens were also included in the morphological characterization: EGS 34015 (CBS 918.96), EGS 34016 (CBS 916.96) (E.G. Simmons, Mycological Services), CBS 124274, and CBS 124278 (CBSKNAW Collection) (Table 1).

Fungal isolates were obtained by dipping tiny rectangular sections $(3 \times 3 \mathrm{~mm})$ of affected leaf tissues into sodium hypochlorite $(1 \%)$ and washing them in sterile water three times. The samples were placed on potato dextrose agar (PDA; Merck, Darmstadt, Germany), supplemented with streptomycin (50 mg per liter; AppliChem $\mathrm{GmbH}$, Darmstadt, Germany). Monoconidial cultures were produced for all the isolates and maintained at $-80^{\circ} \mathrm{C}$ as conidial suspensions in a $30 \%$ glycerol solution. All the species were identified as belonging to the small-spored Alternaria spp. by means of morphological observations (colony and spore characteristics) and comparing them with the reference strains of A. alternata (EGS 34015, EGS 34016, CBS 124278) and A. arborescens (CBS 124274) (Table 1).

DNA extraction and PCR. The DNA of 22 fungal isolates was extracted by means of an E.Z.N.A. Fungal DNA Mini Kit (Omega Bio-Tek, Darmstadt, Germany) using the mycelium (100 mg) grown on PDA, according to the manufacturer's instructions. Molecular identification was performed by amplifying different gene fragments. The internal transcribed spacer (ITS, White et al. 1990), the RNA polymerase second largest subunit (rpb2; Liu et al. 1999; Sung et al. 2007), the endopolygalacturonase (endoPG, Andrew et al. 2009), the translation elongation factor 1-alpha (tef1; Carbone and Kohn 1999), the Alternaria major allergen gene (Alt a 1; Hong et al. 2005), and an anonymous gene region (OPA10-2; Andrew et al. 2009) were amplified using the ITS1/ITS4, RPB2-5F2/fRPB2-7cR, PG3/PG2b, EF1-728F/EF1-986R, Alt-for/Alt-rev, and OPA10-2L/ OPA10-2R primers, respectively. The list of primers used is shown in Supplementary Table S1. The PCR products were purified using a QIAquick PCR purification kit (Qiagen, Hilden, Germany) according to the manufacturer's instructions. The amplicons were sequenced in both directions at BMR Genomics Centre (Padua, Italy). With the exception of a few sequences that had previously been obtained for some isolates (Garibaldi et al. 2018b, c, 2019a, b, c, d, e, 2020a, b, c; Gilardi et al. 2019), the sequences were deposited in GenBank with the following accessions: MN565909-MN565919 (ITS), MN566288-MN566325 (rpb2), MN627291-MN627316 (endoPG), MN627317-MN627354 (tef1), MN615845-MN615879 (Alt a 1), and MN566326-MN566361 (OPA10-2) (Table 1). These accession numbers also comprised the sequences for 19 Alternaria sp. isolates from vegetable and aromatic plants from previous reports (Garibaldi et al. 2019c; Gilardi et al. 2019; Matić et al. 2019) for those genes that were necessary to accomplish six-locus phylogenetic analyses in this study. The reference isolates are also indicated in Table 1 together with their corresponding accession numbers.

Sequence analyses. The sequences of the studied fungal isolates were initially compared with the reference Alternaria isolates (Siciliano et al. 2018; Woudenberg et al. 2015) available in the GenBank database using the BLAST software package (https:// www.ncbi.nlm.nih.gov). Maximum likelihood (ML) and Bayesian inference (BI) phylogenetic analyses were carried out on both single and multilocus sequences, including the corresponding sequences of 44 reference isolates of the Alternaria section. Concatenated data of the ITS, rpb2, endoPG, tef1, Alt a 1, and OPA10-2 sequences included a total of $2,581 \mathrm{bp}$. The ML analysis was performed with MEGA 7 software (Kumar et al. 2016). The best-fit nucleotide model of each dataset for an ML analysis was determined by means of Findmodel (https://www.hiv.lanl.gov/content/sequence/findmodel/findmodel.html): HKY: the Hasegawa-Kishino-Yano parameter for ITS and tefl, TrN: Tamura-Nei plus Gamma for $r p b 2$ and concatenated tree, K80: Kimura (1980) for endoPG, GTR: General Time Reversible for Alt a 1, and K80 plus Gamma for OPA10-2.

The selection of the best-fit model for each sequence set (Huelsenbeck and Ronquist 2001) was carried out, for a Bayesian analysis, using TOPALI v.2.5 (Milne et al. 2004): JC: Jukes and Cantor (1969; ITS and tef1), K80 (endoPG), SYM: symmetrical model ( $r p b 2$ ), SYM plus Gamma (Alt a 1 and OPA10-2), and K80 plus invariable sites plus Gamma (concatenated tree). The first $25 \%$ of the sampled trees were discarded as burn-in phases in the Bayesian analysis, which was followed by an estimation of the successive probabilities for the remaining trees (Ronquist et al. 2009).

Haplotype analyses. A network was generated using the endoPG and OPA10-2 sequences to assess the genealogy patterns of the haplotypes using the PopART v. 1.7 software (http://popart.otago.ac.nz; Leigh and Bryant 2015). A TCS network was used for haplotype identification on the basis of the parsimony probability calculated for pairwise comparisons (Clement et al. 2002; Templeton et al. 1992). DNA polymorphism parameters (haplotype diversity, nucleotide diversity, number of polymorphic sites, mutations, and nucleotide differences) were determined by means of DNA Sequence Polymorphism v. 6 software (Rozas et al. 2017). No haplotype 
analyses were performed for the A. arborescens species complex isolates, due to the limited number of these isolates identified in this study.

Tajima's $D$, Fu's and Li's $D$, and Fu's and Li's $F$ tests determined departures from the null hypothesis of neutral evolution. Significant values of these tests can indicate the presence of population changes such as change in size, population expansion, population contraction, and population subdivision (Fu and Li 1993; Tajima 1989).
Pathogenicity assays. Healthy plants were used for the pathogenicity assays of following ornamental plant species: pineapple sage, fruit-scented sage, purple coneflower, common foxglove, creeping bellflower, common coleus, purple lotus, peppermint, nettle-leaved bellflower, and orange coneflower (F.Lli Airaudi S.a.s., Robassomero, Italy). For each plant species, three plants were used for artificial inoculation of each fungal strain, and three plants as a

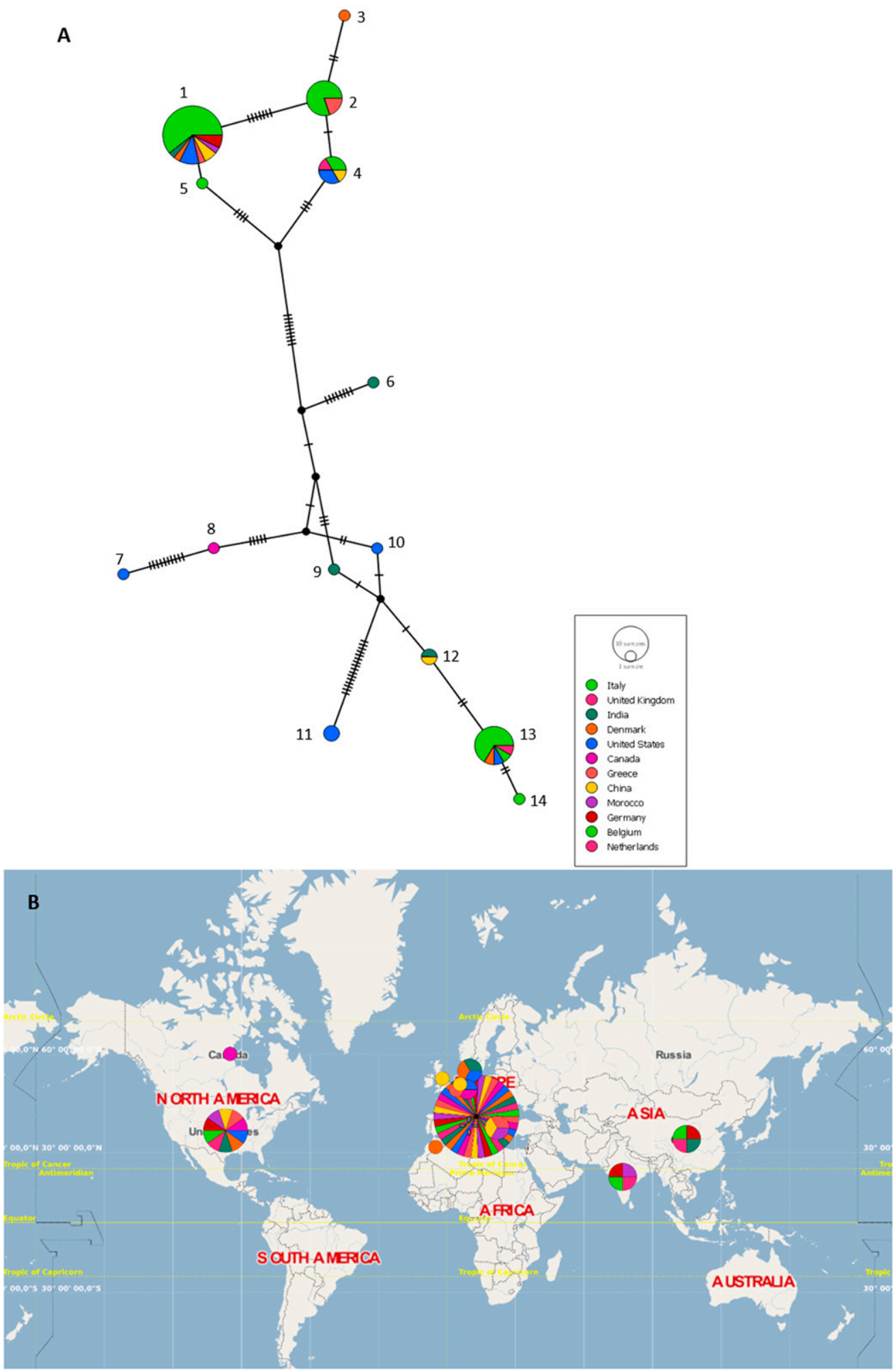

Fig. 2. Haplotype distribution obtained from partial OPA10-2 sequences by means of TCS analyses. A, TCS haplotype network and B, worldwide distribution of haplotypes. Twenty studied and 48 reference isolates of Alternaria alternata were included in the haplotype analysis. Each haplotype is shown with a circle and the size of the circle is proportional to the frequency of the haplotype. 
noninoculated (healthy) control (60 plants in total). The seeds were sown in 2-liter plastic pots containing a disinfested growing medium (60\% peat, $20 \%$ composted broadleaf bark, and 20\% clay; 1 seed/ pot). The plants were maintained in a greenhouse at 22 to $24^{\circ} \mathrm{C}$ for 4 weeks before the inoculation.

Ten A. alternata isolates were grown on potato carrot media (PCA; $20 \mathrm{~g} /$ liter potatoes, $20 \mathrm{~g} /$ liter carrots, and $20 \mathrm{~g} / \mathrm{liter}$ agar) supplemented with $25 \mathrm{mg} /$ liter of streptomycin for 2 weeks under a 12-h photoperiod. Four-week-old seedlings were inoculated by spraying each fungal isolate with a spore suspension of $1 \times 10^{5}$ conidia/ml in single pathogenicity and cross-inoculation assays, with exception of nettle-leaved bellflower and orange coneflower plants on which were not performed the cross-inoculation assays. The plants were covered by a transparent and sterile polyethylene film
61-4

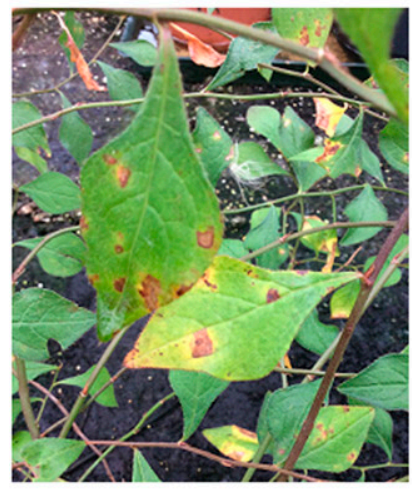

DB18MAG10

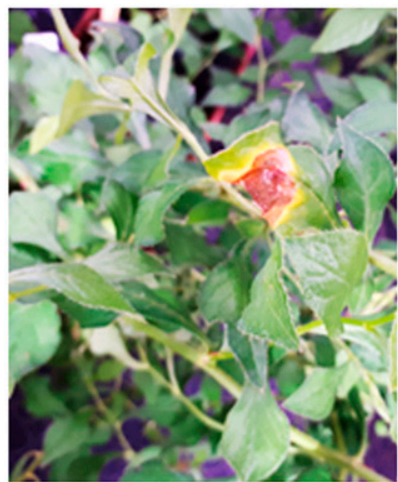

19-38

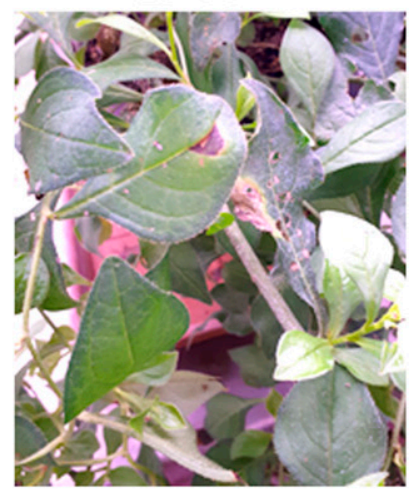

\section{Ceratostigma willmottianum (purple lotus)}

IT61

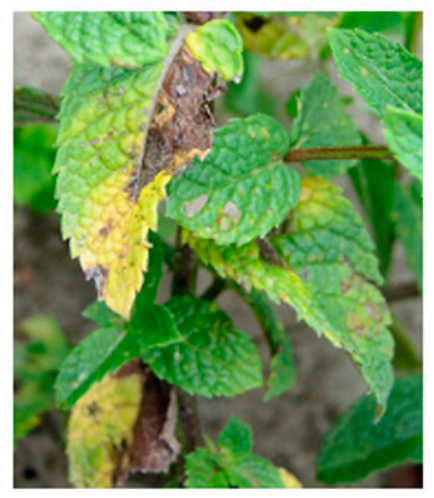

DB18MAG10

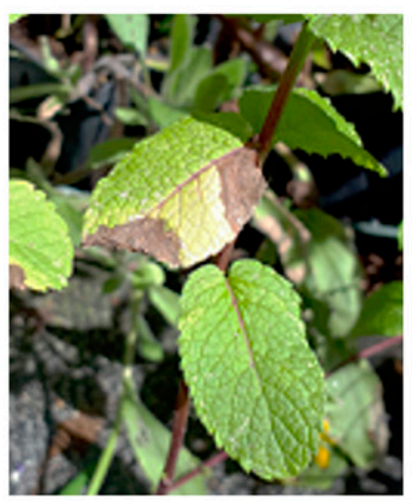

19-38

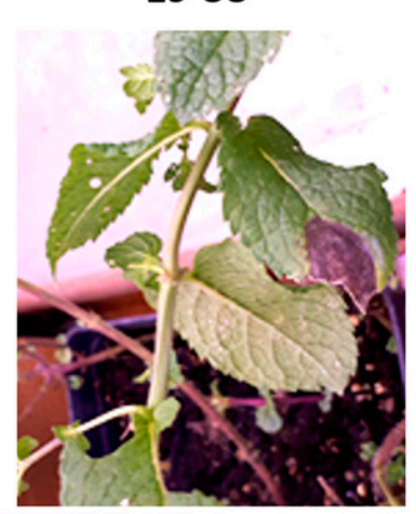

int)
IT44

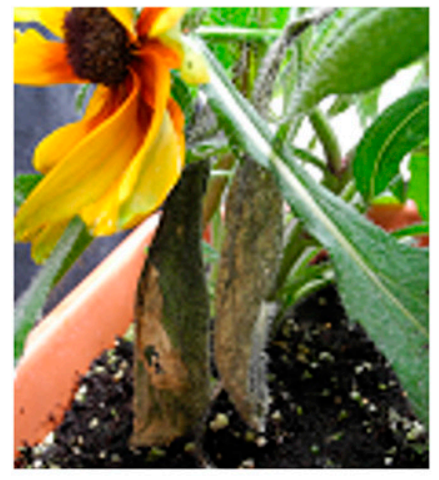

DB18MAG10

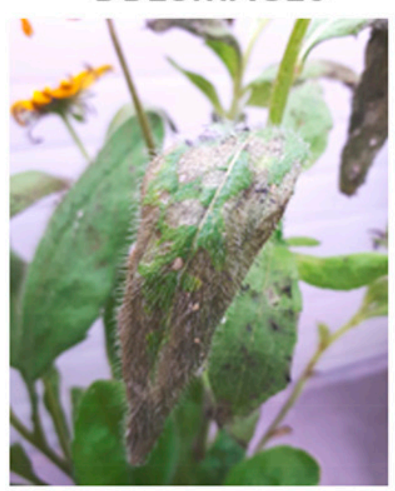

18

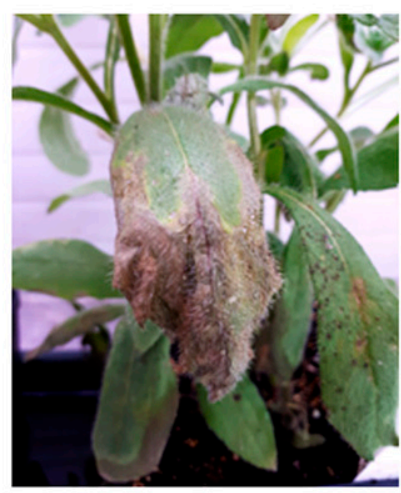

\section{Echinacea purpurea (purple coneflower)}

Fig. 3. Symptomatology on 4-week-old ornamental original and experimental hosts at 1 week postinoculation with Alternaria alternata isolates. The isolates used for the artificial inoculation in the pathogenicity tests are shown at the top of the figure. 
for 1 week to achieve a relative humidity of $100 \%$. The inoculated seedlings were kept in the growth chambers at $25^{\circ} \mathrm{C}$ (day) and $23^{\circ} \mathrm{C}$ (night), for a photoperiod of $12 \mathrm{~h}$, and watered twice per day. No cross-inoculation assays were performed on two $A$. arborescens species complex isolates, while the single pathogenicity tests had already been conducted (Garibaldi et al. 2020a; Garibaldi, personal communication). Reisolations were performed from the leaves of the control plants and plants inoculated with 10 A. alternata isolates.

Disease severity, expressed as percentage of affected leaf area, was measured 2 weeks postinoculation (dpi) considering a 0-5 scale (Siciliano et al. 2018): 0 (no visible symptoms), 1 (up to 5\%), 2 (6 to $10 \%$ ), 3 (11 to $25 \%$ ), 4 (26 to $50 \%$ ), and 5 (51 to 100\%). The search for round brown leaf spots was carried out by examining 10 to 20 leaves per plant. Statistical analyses were performed by using SPSS software (version 24.0, SPSS Inc., Chicago, IL, U.S.A.). Differences in disease severity between $A$. alternata isolates were analyzed using a nonparametric Kruskal-Wallis test at $P=0.05$.

\section{Results}

Morphological, molecular identification, and phylogenetic analyses. Plants of 13 ornamental plant species were found to be severely infected by leaf spots in a private garden in the northern Italian Piedmont region. All the fungal isolates obtained from the Alternaria infected leaf tissues were identified morphologically as being small-spored Alternaria species by observations of their macro and micromorphological characteristics and their comparison with those of the reference strains (A. alternata; EGS 34015, EGS 34016, CBS 124278; and A. arborescens, CBS 124274). Morphological characteristics (mycelium, conidial size, and septation) of selected A. alternata isolates are shown in Supplementary Figure S1 and Supplementary Table S2. Twenty-two of the recovered Alternaria isolates were then used for a molecular characterization. Their ITS, rpb2, endoPG, tefl, Alt a 1, and OPA10-2 sequences showed the highest identity (99 to 100\%) with two Alternaria spp. (A. alternata and A. arborescens) after a comparison with the available sequences at NCBI. The sequences were subjected to six-locus phylogenetic analyses, due to the inconclusiveness of the single gene-based identification.

The concatenated phylogenetic analyses comprised 22 Alternaria isolates from ornamental hosts and 44 reference isolates from ornamentals, vegetables, cereals, and fruit-tree species (Table 1). The ML analyses included around $200 \mathrm{bp}$ for tefl, 300 for Alt a 1 and endoPG, $400 \mathrm{bp}$ for ITS, and 600 to $700 \mathrm{bp}$ for $r p b 2$ and OPA10-2. The ML phylogenetic tree was clearly divided into two major clusters (Fig. 1). The first major cluster was further divided into two subclusters. The first subcluster contained one group of the A. arborescens species complex isolates (including 19-10 from Michaelmas daisy and 456 from pineapple sage) with a high (100\%) bootstrap value, and one group of A. alternata isolates (including the IT61 isolate from peppermint, and the 18 and $18 \mathrm{R}$ isolates from common foxglove). The second subcluster comprised the majority of the ornamental and reference $A$. alternata strains (16 and 27, respectively). The second cluster contained the fruit-scented sage 6-518 isolate together with the A. alternata, A. tomato, and Alternaria sp. reference isolates.

No specific isolate groupings were correlated with plant host or geographical origin. Intraspecies molecular diversity was found for both $A$. alternata and the $A$. arborescens species complex, and various phylogenetic subgroups, containing various hosts of different origin, were also observed. The Bayesian concatenated multilocus tree confirmed the tree topologies obtained by means of the ML analyses, and Bayesian posterior probability values were mainly in accordance with the ML bootstrap values (Fig. 1).

Haplotype analyses: the endoPG and OPA10-2 sequence data sets. The endoPG and OPA10-2 sequences of 68 A. alternata isolates were used for haplotype analyses. Nineteen of the isolates from this study originated from various ornamental hosts in one geographical area (a garden near Biella, northern Italy). The remaining isolates included reference isolates from ornamentals and other plant hosts from 12 countries (including Italy) from different regions throughout the world. Fourteen haplotypes were identified with

Table 3. Reaction of 10 host ornamental species to the Alternaria alternata isolates 2 weeks postinoculation ${ }^{\mathrm{a}}$

\begin{tabular}{|c|c|c|c|c|c|c|c|c|c|c|c|}
\hline Species & Isolate & $\begin{array}{c}\text { Salvia } \\
\text { elegans } \\
\text { (pineapple } \\
\text { sage) }\end{array}$ & $\begin{array}{l}\text { Salvia } \\
\text { dorisiana } \\
\text { (fruit- } \\
\text { scented } \\
\text { sage) }\end{array}$ & $\begin{array}{c}\text { Echinacea } \\
\text { purpurea } \\
\text { (purple } \\
\text { coneflower) }\end{array}$ & $\begin{array}{l}\text { Campanula } \\
\text { rapuncoloides } \\
\text { (creeping } \\
\text { bellflower) }\end{array}$ & $\begin{array}{l}\text { Digitalis } \\
\text { purpurea } \\
\text { (common } \\
\text { foxglove) }\end{array}$ & $\begin{array}{c}\text { Ceratostigma } \\
\text { willmottianum } \\
\text { (purple lotus) }\end{array}$ & $\begin{array}{l}\text { Plectranthus } \\
\text { scutellarioides } \\
\text { (common } \\
\text { coleus) }\end{array}$ & $\begin{array}{c}\text { Mentha } \times \\
\text { piperita } \\
\text { (peppermint) }\end{array}$ & $\begin{array}{c}\text { Campanula } \\
\text { trachelium } \\
\text { (nettle-leaved } \\
\text { bellflower) }\end{array}$ & $\begin{array}{c}\text { Rudbeckia } \\
\text { fulgida } \\
\text { (orange } \\
\text { coneflower) }\end{array}$ \\
\hline $\begin{array}{l}\text { Salvia elegans } \\
\quad \text { (pineapple } \\
\text { sage) }\end{array}$ & DB17GIU22 & +++++ & +++++ & ++++ & +++++ & +++ & - & + & + & NT & NT \\
\hline $\begin{array}{l}\text { Salvia dorisiana } \\
\text { (fruit-scented } \\
\text { sage) }\end{array}$ & DB18MAG21 & +++++ & ++++ & ++++ & ++++ & ++ & ++++ & ++ & +++ & NT & NT \\
\hline $\begin{array}{l}\text { Echinacea } \\
\text { purpurea } \\
\text { (purple } \\
\text { coneflower) }\end{array}$ & IT44 & ++++ & ++++ & +++++ & ++++ & +++ & - & ++++ & +++++ & NT & NT \\
\hline $\begin{array}{l}\text { Campanula } \\
\text { rapunculoides } \\
\text { (creeping } \\
\text { bellflower) }\end{array}$ & IT22 & ++++ & ++++ & ++++ & +++++ & ++++ & +++ & +++ & +++ & NT & NT \\
\hline $\begin{array}{l}\text { Digitalis } \\
\text { purpurea } \\
\text { (common } \\
\text { foxglove) }\end{array}$ & 18 & ++++ & ++++ & +++++ & +++++ & +++ & +++ & +++ & ++ & NT & NT \\
\hline $\begin{array}{l}\text { Ceratostigma } \\
\text { willmottianum } \\
\text { (purple lotus) }\end{array}$ & $61-4$ & +++++ & +++ & +++++ & +++++ & +++ & +++ & ++++ & +++ & NT & NT \\
\hline $\begin{array}{l}\text { Plectranthus } \\
\text { scutellarioides } \\
\text { (common } \\
\text { coleus) }\end{array}$ & DB18MAG10 & ++++ & ++++ & +++++ & +++++ & ++++ & ++ & ++ & +++ & NT & NT \\
\hline $\begin{array}{l}\text { Mentha } \times \\
\quad \text { piperita } \\
\quad \text { (peppermint) }\end{array}$ & IT61 & +++ & +++ & +++ & +++++ & +++ & +++ & ++++ & +++ & NT & NT \\
\hline $\begin{array}{l}\text { Campanula } \\
\text { trachelium } \\
\text { (nettle-leaved } \\
\text { bellflower) }\end{array}$ & $19-11$ & +++++ & + & ++ & +++ & - & - & +++ & NT & +++++ & NT \\
\hline $\begin{array}{l}\text { Rudbeckia } \\
\text { fulgida } \\
\text { (orange } \\
\text { coneflower) }\end{array}$ & $19-38$ & +++ & +++ & - & +++++ & +++ & +++++ & - & ++++ & NT & +++ \\
\hline
\end{tabular}


OPA10-2 sequences, including three haplotypes comprising the studied isolates from the ornamental hosts (Table 2). Eleven haplotypes were identified on the basis of endoPG sequences, and of these, four haplotypes included the isolates from ornamental hosts (Table 2).
Haplotype 1 (41 isolates for endoPG and 28 isolates for OPA10-2) was the most abundant haplotype, and it included, in both data sets, the majority of the Italian isolates from the ornamentals along with the reference isolates from other ornamental and leafy vegetable hosts (from Italy, Greece, Morocco, Denmark, Germany, the
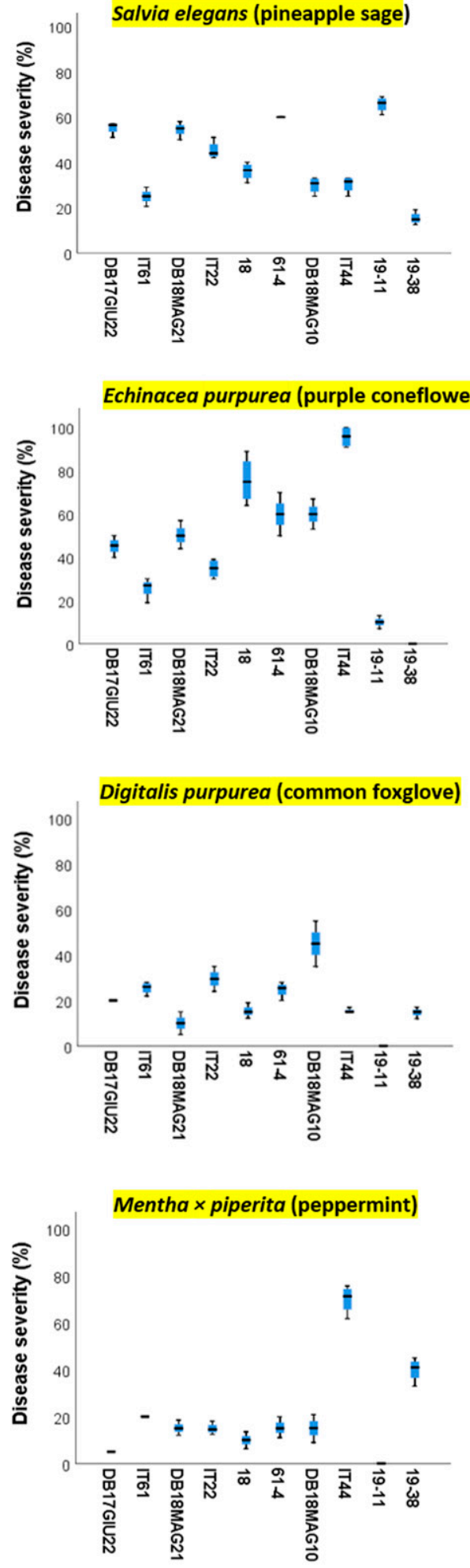
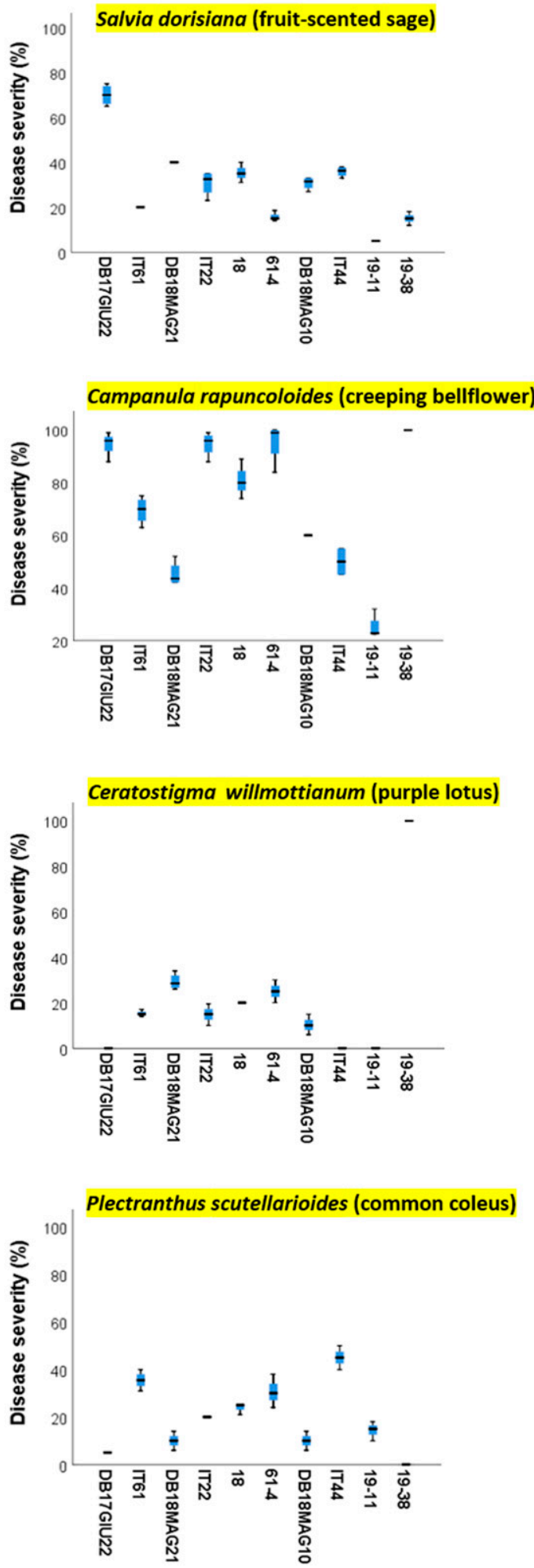

Fig. 4. Box plots showing disease severity on artificially inoculated ornamental species between different Alternaria alternata isolates in simple and cross-pathogenicity assays. Disease severity was calculated at 2 weeks postinoculation and expressed as a percentage. Boxes show the interquartile range, and a line within the box indicate the median value. Kruskal-Wallis test for disease severity was carried out with multiple comparisons between $10 \mathrm{~A}$. alternata isolates on inoculated ornamental species, and a statistically significant difference was accepted at $P<0.05$. 
U.S.A., and China) (Fig. 2 and Supplementary Fig. S2). The other two major haplotypes were Hap 2 and Hap 13 for OPA10-2. Haplotype 2 comprised the isolates from three ornamental hosts (calliopsis, creeping bellflower, and nettle-leaved bellflower) together with Italian isolates from cauliflower, basil, and chili pepper, as well as Greek isolates from Punica granatum and Prunus sp. Haplotype 13 grouped the Italian isolates from common foxglove, peppermint, cabbage, and spinach together with the Belgian isolate from strawberry, the Danish isolate from Prunus sp., the U.S.A. isolate from Plantago aristida, and Italian and Dutch isolates of unknown origin. As far as the endoPG sequences are concerned, apart from haplotype 1 (the main haplotype), another major haplotype (Hap 8) was also observed. Haplotype 8 comprised Italian isolate REIS 68 from purple lotus together with seven reference isolates from different hosts (vegetables, ornamentals, and cereals) and different origins (Italy, Canada, the U.S.A., China, and India).

None of the studied Italian isolates from the ornamentals created a unique haplotype and they always grouped with the isolates from other hosts. On the other hand, seven unique OPA10-2 haplotypes and four unique endoPG haplotypes were obtained from reference isolates originating from Denmark, Italy, Belgium, Germany, Canada, the U.S.A., and India. A weak correspondence of the geographic origin and the haplotype was observed, and the haplotypes generally contained isolates from various countries (Fig. 2 and Supplementary Fig. 2). The only haplotypes restricted to one country (with the exception of the unique haplotypes) were Hap 11 (OPA10-2) and Hap 6 (endoPG), which comprised two American isolates (leafy spurge and carrot), and two Italian isolates from oregano and cauliflower, respectively. Furthermore, no affinity between the haplotype and the plant host was observed, and the isolates from the ornamentals, vegetables, cereals, and fruit trees were found together within the different haplotypes.

The identified haplotypes were not associated with insertion/ deletion mutations, since no InDel haplotypes were found for either of the studied regions by the DNASP software. Instead, the haplotypes, apart from being associated with other types of mutations, were also found to be associated with singleton variable sites. Overall, a high degree of haplotype diversity $(\mathrm{Hd})$ was found $(0.783$ for OPA10-2 and 0.626 for endoPG) as well as a low degree of nucleotide diversity per site $(\pi)$ (0.02 for OPA10-2 and 0.01 for endoPG). Neutrality was rejected $(P<0.05)$ for endoPG in contrast to OPA10-2. Tajima's $D$, Fu's and Li's $D$, and Fu's and Li's $F$ tests were significantly negative for endoPG indicating the occurrence of a population expansion or selective processes (Supplementary Table S3).

Pathogenicity assays. The initial symptoms appeared as tiny, round, necrotic spots on the leaves, which gradually expanded and occasionally became confined by the leaf veins at 7 dpi (Fig. 3). The necrosis was spread across the leaves (completely or partially) at $15 \mathrm{dpi}$, and this eventually led to plant collapse. Apart from the ability to cause leaf spot on the original isolation host, eight of the studied isolates were found, in cross-inoculation pathogenicity assays, to be capable of causing similar symptoms on the majority of the other ornamental hosts (Table 3; Fig. 3). Furthermore, reisolations from symptomless leaves of the control plants yielded negative results, while those from diseased plants showed that all fungal isolates belonged to the small-spored Alternaria spp.

The highest disease severity was observed on creeping bellflower and purple lotus (100\% for both), followed by purple coneflower (95\%), fruit-scented sage, and peppermint (70\% for both), 2 weeks after inoculation by some isolates (Fig. 4). The isolates producing the most severe symptoms were 19-38 (from orange coneflower) on creeping bellflower and purple lotus, and IT44 (from purple coneflower) on purple coneflower and peppermint (Table 3; Fig. 4). Kruskal-Wallis test for disease severity carried out with multiple comparisons between different $A$. alternata isolates on inoculated ornamental species evidenced statistically significant differences between the isolates (Supplementary Table S4). All the isolates caused Alternaria leaf spot on all of the tested hosts, with the exception of isolates DB17GIU22 and IT44 on purple lotus, the 19-11 isolate on purple lotus, common foxglove, and peppermint hosts, and the 19-38 isolate on purple coneflower and common coleus. In general, the isolates were more aggressive on the 'nonoriginal' ornamental hosts than on the original isolation hosts (Fig. 4).

The highest plant mortality was noted on creeping bellflower inoculated with $A$. alternata isolates from 'nonoriginal' hosts (orange coneflower 19-38, peppermint IT61, and pineapple sage DB17GIU22; 100, 70 , and $55 \%$, respectively), followed by the 'original' creeping bellflower IT22 isolate ( $45 \%$ plant mortality). Plant death was also observed in a sizeable number of purple coneflower and nettleleaved bellflower plants inoculated with their original isolates (70 and $40 \%$, respectively).

\section{Discussion}

In this study, 22 Alternaria isolates, originating from one geographical area (the Piedmont region) and isolated within a 3-year period from 13 hosts, have been identified as the causative agents of a number of Alternaria leaf spot disease of ornamentals. Disease was caused by A. alternata on all the ornamental hosts, with the exception of Michaelmas daisy, where disease was caused by the A. arborescens species complex, and of pineapple sage, where both fungi were found to be agents of disease. The results presented here represent the first record of A. alternata on orange coneflower and of A. arborescens on pineapple sage in Italy, as well as in the world (Farr and Rossman 2020).

The six-locus (ITS, rpb2, endoPG, tef1, Alt a 1, and OPA10-2) phylogenetic analyses carried out as part of this research allowed 19 ornamental isolates to be identified as A. alternata, and two ornamental isolates to be identified as members of the A. arborescens species complex. This confirms the necessity of multilocus species identification of the Alternaria section, due to the low resolution of the standard barcode-based species identification of small-spored Alternaria species belonging to Alternaria sect. Alternaria (Lawrence et al. 2013; Peever et al. 2004; Pryor and Michailides 2002; Woudenberg et al. 2015). The concatenated phylogenetic analyses in this study are in agreement with other multilocus studies, which have shown a clear separation of A. alternata from the A. arborescens species complex (Al-Nadabi et al. 2018; Elfar et al. 2018; Woudenberg et al. 2015; Zhu and Xiao 2015). These analyses utilized a combination of the slowly evolving genes (tef1, RPB2; Stielow et al. 2015), the faster evolving genes (ITS, Alt a 1, endoPG; Hong et al. 2005; O'Toole et al. 2018; Stielow et al. 2015), and an anonymous OPA10-2 region (Andrew et al. 2009), that were sufficiently variable to distinguish two major members of the Alternaria section Alternata. However, it was not possible to precisely identify one ornamental isolate (6-518 from fruitscented sage) using this multilocus approach. This isolate was grouped in a distinct subcluster, together with reference isolates of A. alternata (CBS_82668 and CBS_119408), A. tomato (CBS_10330), and Alternaria sp. (basBIO_10). Further molecular analyses are necessary to precisely identify this isolate, as well as the bas BIO 10 isolate that was not clearly identified in this or in a previous study (Matić et al. 2019). These analyses will need the inclusion of additional molecular markers, such as glyceraldehyde-3phosphate dehydrogenase (gapdh), 18S nrDNA (SSU), 28S nrDNA (LSU), the plasma membrane ATPase, and calmodulin ( $\mathrm{cmdA}$ ), as suggested by Woudenberg et al. (2015) and Zhu and Xiao (2015).

In this study, the haplotype analyses show that the major haplotypes regarding both the OPA10-2 and endoPG sequences are shared among isolates from multiple countries (including Italy), and that no important affinity was found between the geographic origin and the haplotype assignment. Only two exceptions emerged where the haplotype was closely related to the geographic location, that is, Hap 11 in OPA10-2 (restricted to the U.S.A.), and Hap 6 in endoPG (confined to Italy). Our results are consistent with those reported by Andrew et al. (2009), who found no association of geographic location and identified haplotype for the A. alternata and A. arborescens species complex populations from eight countries. Interestingly, an almost identical haplotype incidence was observed in the endoPG (16\%) and OPA10-2 regions (20\%) after normalizing the data of this study with those of the Andrew et al. (2009) study. A higher 
haplotype diversity was obtained for OPA10-2 than for endoPG, which is not surprising, since the genetic variability in protein coding portions is lower than in the intergenic and intron regions (Tatarinova et al. 2016). This confirms the suitability of the OPA10-2 region for studying the haplotype diversity of A. alternata.

Haplotypes containing only ornamental hosts from Italy were not observed in this research, which could suggest that a sufficient specialization of the fungus has not yet occurred on ornamentals in this geographical area. These results are also in agreement with published haplotype network results, which showed that A. alternata populations from fruit tree and forest tree hosts (Andrew et al. 2009) as well as from tomato, pepper, and wheat (da Cruz Cabral et al. 2017) were polyphagous and not host-specific.

The major haplotype, that is, halotype 1, was observed for OPA10-2 in the external part of the haplotype network, and was differentiated, with a few mutation events, from the other haplotypes. It was composed of multiple hosts from Italy (the majority of ornamentals in this study, the reference isolate CBS_117130 from strawberry tree and a few vegetable isolates) as well as other isolates from ornamentals, fruit trees, and vegetables originating from China, the U.S.A., Morocco, Greece, Germany, Denmark, and India. This could mean that this predominant haplotype represents the ancient haplotype that has lasted in the population for a very long time, since older haplotypes (those which show a higher frequency) presumably have a wider geographic distribution (Freeland 2005). The remaining haplotypes (minor) could represent lineages that have evolved more recently. The major haplotype in the endoPG haplotype network, that is, haplotype 1, shows a more central distribution, but it shares multiple geographic origins with major haplotype 1 in the OPA10-2 region, for example, in Italy, Greece, Denmark, Germany, the U.S.A., Morocco, and China. The different position of the major haplotype in these two networks may be attributed to the higher conservation of the protein-coding gene (endoPG), from which multiple, rare haplotypes, with one to two mutations, were formed externally, whereas the OPA10-2 region is an anonymous locus and is separated from other haplotypes with a much higher number of mutations.

A. alternata spores from infected plants may be transmitted by wind (Bashan et al. 1991; Fernández-Rodríguez et al. 2015; GrinnGofron et al. 2016), while the seed transmission of the fungus is facilitated by the globalization of the seed market (Gilardi et al. 2013; Gullino et al. 2014; Mangwende et al. 2018; Parisi et al. 2018). Therefore, wind dispersal and the exchange of infected seeds may contribute to wide geographic distribution of A. alternata, as emphasized by the results of this study that showed the lack of geographic structuring in the haplotypes. The spread of inoculum from other hosts, accompanied by the low host specificity, may explain the observed transmission of the fungus from leafy vegetables to ornamentals in a relatively short period of time (a few years), and the inducement of similar Alternaria leaf spot diseases. Whether this can be stimulated by climatic changes requires further investigation. However, it has already been reported that A. alternata increases in growth rate, spore production, and causes a higher disease index as a result of an increase in temperature and/or $\mathrm{CO}_{2}$ concentrations (Damialis et al. 2015; Grinn-Gofroń et al. 2016; Siciliano et al. 2017; Wolf et al. 2010).

With regard to the neutrality tests, negative but significant values were obtained for Fu's D and Li's D statistics, which should indicate a similar population expansion or purifying (negative) selection in $A$. alternata to the ones reported in recent studies for endoPG (Andrew et al. 2009; Stewart et al. 2014). The observed relatively high haplotype diversity and low nucleotide diversity might be related to the high inoculum dispersal rate, which may also have been influenced by population expansion.

The A. alternata and A. arborescens species complex isolates were single isolates obtained from different plants, but all of them were found to be capable of causing Alternaria leaf spot disease. Further studies, in which more fungal isolates should be included and pathogenicity assays should be run, are necessary to investigate whether a mixed infection of these two fungi exists and whether it could have a possible involvement in the spread of these diseases.
Apart from the observed leaf spot symptoms on the original isolation host, the tested A. alternata isolates were able to cause similar symptoms on most of the experimental ornamental hosts, thereby indicating the potential risk of their spread to other ornamentals in field conditions, as already observed on leafy vegetable hosts (Matić et al. 2019).

It has been reported that fungal necrotrophs, such as A. alternata, produce phytotoxins (host-specific or non-host-specific) that are indispensable for pathogenicity. In the case of A. alternata, various host-selective effectors trigger immunity of the plant host and the expression of NLR resistance genes, thus inducing susceptibility in only a particular host species but not in others (Meng et al. 2018; Wang et al. 2014). Some possible explanations as to why A. alternata spread relatively fast on new ornamentals hosts in a 5,000 $\mathrm{m}^{2}$ garden could be: environmental changes and their effect on inoculum abundance, the possible presence of as yet unidentified non-host-specific mycotoxins in these fungus populations, and the modification of the chitin perception of Alternaria spp. by plant defense machinery, as already reported (Andersen et al. 2009; Schiro et al. 2018; Wan et al. 2012; Yamada et al. 2016).

The relatively high level of genetic diversity of the A. alternata isolates found in this study suggests the possibility of the occurrence of a sexual and/or parasexual recombination, although a sexual stage of the fungus has not yet been found under natural or experimental conditions. The equal distribution of both MAT1-1 and MAT1-2 genes that has recently been found within and between populations, together with the existence of random associations between neutral markers in A. alternata populations, and the recombination between isolates of the same mating type may suggest an important role of a sexual/parasexual recombination in the evolution and spread of $A$. alternata (Meng et al. 2015; Stewart et al. 2013; Yang et al. 2018).

In conclusion, this study has shown that $A$. alternata and the $A$. arborescens species complex are the causal agents of a number of emerging Alternaria leaf spot diseases of ornamentals in northern Italy. The polyphagous nature of Alternaria and its lack of geographic restrictions, supported by the grouping of the isolates of different plant groups and various geographic locations in both phylogenetic and haplotype analyses, are key factors that need to be taken into account for a successful management of the disease. The sanitary status of seeds should be ameliorated, and stricter seed control measures need to be applied. The appropriate choice of ecosustainable fungicides is also essential, taking into consideration the presence of certain Alternaria populations that are resistant to particular fungicides on other crops, and their possible transmission to ornamentals. This, together with the use of resistant cultivars, the application of biological control agents, and the rotation of different chemistries with different modes of action, may help achieve an efficient management of Alternaria diseases on ornamentals and other hosts.

\section{Acknowledgments}

The authors would like to thank Dr. V. Guarnaccia (University of Turin, Grugliasco (TO), Italy) for helpful comments during preparation of the manuscript, and to the anonymous referees for their valuable comments. The authors also wish to thank Marguerite Jones for the language revision.

\section{Literature Cited}

Al-Nadabi, H. H., Maharachchikumbura, S. S. N., Agrama, H., Al-Azri, M., Nasehi, A., and Al-Sadi, A. M. 2018. Molecular characterization and pathogenicity of Alternaria species on wheat and date palms in Oman. Eur. J. Plant Pathol. 152:577-588.

Andersen, B., Sørensen, J. L., Nielsen, K. F., Gerrits van den Ende, B., and de Hoog, S. 2009. A polyphasic approach to the taxonomy of the Alternaria infectoria species-group. Fungal Genet. Biol. 46:642-656.

Andrew, M., Peever, T. L., and Pryor, B. M. 2009. An expanded multilocus phylogeny does not resolve morphological species within the small-spored Alternaria species complex. Mycologia 101:95-109.

Armitage, A. D., Cockerton, H. M., Sreenivasaprasad, S., Woodhall, J., Lane, C. R., Harrison, R. J., and Clarkson, J. P. 2020. Genomics evolutionary history and diagnostics of the Alternaria alternata species group including apple and Asian pear pathotypes. Front. Microbiol. 10:3124.

Bashan, Y., Levanony, H., and Or, R. 1991. Wind dispersal of Alternaria alternata, a cause of leaf blight of cotton. J. Phytopathol. 133:225-238. 
Carbone, I., and Kohn, L. M. 1999. A method for designing primer sets for speciation studies in filamentous ascomycetes. Mycologia 91:553-556.

Chung, K. R. 2012. Stress response and pathogenicity of the necrotrophic fungal pathogen Alternaria alternata. Scientifica (Cairo) 2012:635431.

Clement, M., Snell, Q., Walke, P., Posada, D., and Crandall, K. 2002. TCS: Estimating gene genealogies. Proc. 16th Int. Parallel Distrib. Process Symp. 2:184.

da Cruz Cabral, L., Rodriguero, M., Stenglein, S., Fog Nielsen, K., and Patriarca, A. 2017. Characterization of small-spored Alternaria from Argentinean crops through a polyphasic approach. Int. J. Food Microbiol. 257:206-215.

Damialis, A., Mohammad, A. B., Halley, J. M., and Gange, A. C. 2015. Fungi in a changing world: growth rates will be elevated, but spore production may decrease in future climates. Int. J. Biometeorol. 59:1157-1167.

De Saeger, S., and Logrieco, A. 2017. Report from the 1st MYCOKEY International Conference Global Mycotoxin Reduction in the Food and Feed Chain held in Ghent, Belgium, 11-14 September 2017. Toxins (Basel) 9:pii: E276.

Elfar, K., Zoffoli, J. P., and Latorre, B. A. 2018. Identification and characterization of Alternaria species associated with moldy core of apple in Chile. Plant Dis. 102:2158-2169.

Farr, D. F., and Rossman, A. Y. 2020. Fungal Databases, U.S. National Fungus Collections, ARS, USDA. Retrieved February 16, 2020, from https://nt.arsgrin.gov/fungaldatabases/

Fernández-Rodríguez, S., Sadyś, M., Smith, M., Tormo-Molina, R., Skjøth, C. A., Maya-Manzano, J. M., Silva-Palacios, I., and Gonzalo-Garijo, Á. 2015. Potential sources of airborne Alternaria spp. spores in South-west Spain. Sci. Total Environ. 533:165-176.

Freeland, J. R. 2005. Molecular Ecology. John Wiley \& Sons, Ltd, West Sussex, England.

Freire, M. G., Mussi-Dias, V., Mattoso, T. C., Henk, D. A., Mendes, A. C., Macedo, M. L., Turatti, C., Machado, S. W., and Samuels, R. I. 2017. Survey of endophytic Alternaria species isolated from plants in the Brazilian restinga biome. IOSR J. Pharm. Biol. Sci. 12:84-94.

Fu, Y. X., and Li, W. H. 1993. Statistical tests of neutrality of mutations. Genetics 133:693-709.

Garibaldi, A., Bertetti, D., Gilardi, G., Franco Ortega, S., and Gullino, M. L. 2015. First report of a leaf spot caused by Alternaria sp. on Rudbeckia fulgida in Italy. Plant Pathol. 97:400.

Garibaldi, A., Bertetti, D., Matic, S., and Gullino, M. L. 2018a. First report of leaf spot of Salvia elegans caused by Alternaria alternata in Italy. Plant Dis. 102: 1034.

Garibaldi, A., Bertetti, D., Matic, S., Luongo, I., and Gullino, M. L. 2019a. First report of Alternaria alternata on Campanula rapunculoides in Italy. Plant Dis. 103:368.

Garibaldi, A., Bertetti, D., Matic, S., Luongo, I., and Gullino, M. L. 2019b. First report of leaf necrosis of Salvia dorisiana caused by Alternaria alternata in Italy. Plant Dis. 103:1025.

Garibaldi, A., Bertetti, D., Matic, S., Luongo, I., and Gullino, M. L. 2020a. First report of leaf spots caused by Alternaria arborescens on Symphyotrichum novi-belgii in Italy. Plant Dis. 104:281.

Garibaldi, A., Bertetti, D., Matic S., Luongo, I., and Gullino, M. L. 2020b. First report of leaf necrosis caused by Alternaria alternata on Plectranthus scutellarioides in Italy. Plant Dis. 104:590.

Garibaldi, A., Gilardi, G., Bertoldo, C., and Gullino, M. L. 2011. First report of a leaf spot of sweet basil (Ocimum basilicum) caused by Alternaria alternata in Italy. J. Plant Pathol. 93:S4.71.

Garibaldi, A., Gilardi, G., Matic, S., and Gullino, M. L. 2018b. First report of leaf spot of peppermint (Mentha $\times$ piperita) caused by Alternaria alternata in Italy. Plant Dis. 102:1041.

Garibaldi, A., Gilardi, G., Matic, S., and Gullino, M. L. 2018c. First report of leaf spot caused by Alternaria alternata on Echinacea purpurea in Italy. Plant Dis. 102:1450.

Garibaldi, A., Gilardi, G., Matic, S., and Gullino, M. L. 2019c. First Report of Alternaria alternata on Chili Pepper (Capsicum frutescens) in Italy. Plant Dis. 103:1024

Garibaldi, A., Gilardi, G., Matic, S., and Gullino, M. L. 2019d. First report of Alternaria alternata causing leaf spot on Digitalis purpurea in Italy. Plant Dis. 103:1770.

Garibaldi, A., Gilardi, G., Matic, S., Luongo, I., and Gullino, M. L. 2019e. First report of leaf necrosis caused by Alternaria alternata on Ceratostigma willmottianum in Italy. Plant Dis. 103:1412.

Garibaldi, A., Gilardi, G., Matic, S., Luongo, I., and Gullino, M. L. 2020c. First report of leaf spot of Alcea rosea L. caused by Alternaria alternata in Italy. Plant Dis. 104:588.

Gilardi, G., Gullino, M. L., and Garibaldi, A. 2013. Occurrence of Alternaria spp. in the seeds of basil and its pathogenicity. J. Plant Pathol. 95:41-47.

Gilardi, G., Gullino, M. L., and Garibaldi, A. 2018. Emerging foliar and soil-borne pathogens of leafy vegetable crops: a possible threat to Europe. Bull. OEPP/ EPPO Bull. 48:116-127.

Gilardi, G., Matic, S., Gullino, M. L., and Garibaldi, A. 2019. First report of Alternaria alternata causing leaf spot on spinach (Spinacia oleracea) in Italy. Plant Dis. 103:2133.

Grinn-Gofroń, A., Strzelczak, A., Stępalska, D., and Myszkowska, D. 2016. A 10-year study of Alternaria and Cladosporium in two Polish cities
(Szczecin and Cracow) and relationship with the meteorological parameters. Aerobiologia 32:83-94.

Gullino, M. L., Gilardi, G., and Garibaldi, A. 2014. Seed-borne fungal pathogens of leafy vegetable crops. Pages 47-56 in: Global Perspectives on the Health of Seeds and Plant Propagation Material. M. L. Gullino and G. Munkvold, eds. Springer, Dordrecht, The Netherlands.

Gullino, M. L., Gilardi, G., and Garibaldi, A. 2019. Ready-to-eat salad crops: A plant pathogen's heaven. Plant Dis. 103:2153-2170.

Hong, S. G., Cramer, R. A., Lawrence, C. B., and Pryor, B. M. 2005. Alt a 1 allergen homologs from Alternaria and related taxa: analysis of phylogenetic content and secondary structure. Fungal Genet. Biol. 42:119-129.

Huelsenbeck, J. P., and Ronquist, F. 2001. MRBAYES: Bayesian inference of phylogenetic trees. Bioinformatics 17:754-755.

Jukes, T. H., and Cantor, C. R. 1969. Evolution of protein molecules. Pages 21-132 in: Mammalian Protein Metabolism. H. N. Munro, ed. Academic Press, New York.

Kimura, M. 1980. A simple method for estimating evolutionary rates of base substitutions through comparative studies of nucleotide sequences. J. Mol Evol. 16:111-120.

Kumar, S., Stecher, G., and Tamura, K. 2016. MEGA7: Molecular Evolutionary Genetics Analysis Version 7.0 for Bigger Datasets. Mol. Biol. Evol. 33: $1870-1874$.

Laemmlen, F. 2001. Alternaria diseases. Publ. no. 8040. Regents of University of California, Division of Agriculture and Natural Resources, Oakland, CA, U.S.A.

Lawrence, D. P., Gannibal, P. B., Peever, T. L., and Pryor, B. M. 2013. The sections of Alternaria: formalizing species-group concepts. Mycologia 105:530-546.

Leigh, J. W., and Bryant, D. 2015. PopART: Full-feature software for haplotype network construction. Methods Ecol. Evol. 6:1110-1116.

Liu, Y. J., Whelen, S., and Hall, B. D. 1999. Phylogenetic relationships among ascomycetes: evidence from an RNA polymerase II subunit. Mol. Biol. Evol. 16:1799-1808

Mangwende, E., Kritzinger, Q., Truter, M., and Aveling, T. A. S. 2018. Alternaria alternata: A new seed-transmitted disease of coriander in South Africa. Eur. J. Plant Pathol. 152:409-416.

Matić, S., Gilardi, G., Varveri, M., Garibaldi, A., and Gullino, M. L. 2019 Molecular diversity of Alternaria spp. from leafy vegetable crops and their sensitivity to azoxystrobin and boscalid. Phytopathol. Mediterr. 58:519-533.

Meng, D., Li, C., Park, H. J., González, J., Wang, J., Dandekar, A. M., Turgeon, B. G., and Cheng, L. 2018. Sorbitol modulates resistance to Alternaria alternata by regulating the expression of an NLR resistance gene in apple. Plant Cell 30:1562-1581.

Meng, J. W., Zhu, W., He, M. H., Wu, E. J., Duan, G. H., Xie, Y. K., Jin, Y. J., Yang, L. N., Shang, L. P., and Zhan, J. 2015. Population genetic analysis reveals cryptic sex in the phytopathogenic fungus Alternaria alternata. Sci. Rep. 5:18250.

Milne, I., Wright, F., Rowe, G., Marshall, D. F., Husmeier, D., and McGuire, G 2004. TOPALi: software for automatic identification of recombinan sequences within DNA multiple alignments. Bioinformatics 20:1806-1807.

O'Hara, N. B., Rest, J. S., and Franks, S. J. 2016. Factors affecting the disease severity of Alternaria blackspot in natural Brassica rapa populations on the California and Oregon coasts. Madroño. Evolution 70:241-248.

O'Toole, Á. N., Hurst, L. D., and McLysaght, A. 2018. Faster evolving primate genes are more likely to duplicate. Mol. Biol. Evol. 35:107-118.

Parisi, J. J., Fischer, I. H., Medina, P. F., Firmino, A. C., and Meletti, L. M. 2018 Pathogenicity and transmission of fungi detected on Passiflora alata seeds. Arq. Inst. Biol. (Sao Paulo) 85:e0702017.

Pavón, M. Á, Gonzàlez, I., Martín, R., and García, T. 2015. Alternaria spp. and mycotoxins. Pages 139-150 in: Molecular Biology of Food and Water Borne Mycotoxigenic and Mycotic Fungi. R. Russell, M. Paterson, and N. Lima, eds. CRC Press, Boca Raton, FL, USA.

Peever, T. L., Su, G., Carpenter-Boggs, L., and Timmer, L. W. 2004. Molecular systematics of citrus-associated Alternaria species. Mycologia 96:119-134.

Pryor, B. M., and Michailides, T. J. 2002. Morphological, pathogenic, and molecular characterization of Alternaria isolates associated with Alternaria late blight of pistachio. Phytopathology 92:406-416.

Pugliese, M., Cogliati, E., Gullino, M. L., and Garibaldi, A. 2012. Effect of climate change on Alternaria leaf spot of rocket salad and black spot of basil under controlled environment. Commun. Agric. Appl. Biol. Sci. 77:241-244.

Ronquist, F., van der Mark, P., and Huelsenbeck, J. P. 2009. Bayesian phylogenetic analysis using MRBAYES: theory. Pages 210-266 in: The Phylogenetic Handbook: A Practical Approach to Phylogenetic Analysis and Hypothesis Testing. P. Lemey, M. Salemi, and A.-M. Vandamme, eds. Cambridge University Press, Cambridge, UK.

Rozas, J., Ferrer-Mata, A., Sánchez-DelBarrio, J. C., Guirao-Rico, S., Librado, P. Ramos-Onsins, S. E., and Sánchez-Gracia, A. 2017. DnaSP 6: DNA sequence polymorphism analysis of large datasets. Mol. Biol. Evol. 34:3299-3302.

Schiro, G., Verch, G., Grimm, V., and Müller, M. E. H. 2018. Alternaria and Fusarium fungi: Differences in distribution and spore deposition in a topographically heterogeneous wheat field. J. Fungi (Basel) 4:63.

Siciliano, I., Berta, F., Bosio, P., Gullino, M. L., and Garibaldi, A. 2017. Effect of different temperatures and $\mathrm{CO}_{2}$ levels on Alternaria toxins produced on cultivated rocket, cabbage and cauliflower. World Mycotoxin J. 10:63-71. 
Siciliano, I., Franco Ortega, S., Gilardi, G., Bosio, P., Garibaldi, A., and Gullino, M. L. 2018. Molecular phylogeny and characterization of secondary metabolite profile of plant pathogenic Alternaria species isolated from basil. Food Microbiol. 73:264-274.

Skjøth, C. A., Damialis, A., Belmonte, J., De Linares, C., Fernández-Rodríguez, S., Grinn-Gofroń, A., Jedryczka, M., Kasprzyk, I., Magyar, D., Myszkowska, D., Oliver, G., Paldy, A., Pashley, C., Rasmussen, K., Satchwell, J., Thibaudon, M., Tormo-Molina, R., Vokou, D., Ziemianin, M., and Werner, M. 2016. Alternaria spores in the air across Europe: abundance, seasonality and relationships with climate, meteorology and local environment. Aerobiologia 32:3-22.

Stewart, J. E., Thomas, K. A., Lawrence, C. B., Dang, H., Pryor, B. M., Timmer, L. M., and Peever, T. L. 2013. Signatures of recombination in clonal lineages of the citrus brown spot pathogen, Alternaria alternata sensu lato. Phytopathology 103:741-749.

Stewart, J. E., Timmer, L. W., Lawrence, C. B., Pryor, B. M., and Peever, T. L. 2014. Discord between morphological and phylogenetic species boundaries: incomplete lineage sorting and recombination results in fuzzy species boundaries in an asexual fungal pathogen. BMC Evol. Biol. 14:38.

Stielow, J. B., Levesque, C. A., Seifert, K. A., Meyer, W., Iriny, L., Smits, D., Renfurm, R., Verkley, G. J., Groenewald, M., Chaduli, D., Lomascolo, A., Welti, S., Lesage-Meessen, L., Favel, A., Al-Hatmi, A. M., Damm, U., Yilmaz, N., Houbraken, J., Lombard, L., Quaedvlieg, W., Binder, M., Vaas, L. A., Vu, D., Yurkov, A., Begerow, D., Roehl, O., Guerreiro, M., Fonseca, A., Samerpitak, K., van Diepeningen, A. D., Dolatabadi, S., Moreno, L., Casaregola, S., Mallet, S., Jacques, N., Roscini, L., Egidi, E., Bizet, C., GarciaHermoso, D., Martín, M. P., Deng, S., Groenewald, J. Z., Boekhout, T., de Beer, Z. W., Barnes, I., Duong, T. A., Wingfield, M. J., de Hoog, G. S., Crous, P. W., Lewis, C. T., Hambleton, S., Moussa, T. A., Al-Zahrani, H. S., Almaghrabi, O. A., Louis-Seize, G., Assabgui, R., McCormick, W., Omer, G., Dukik, K., Cardinali, G., Eberhardt, U., de Vries, M., and Robert, V. 2015. One fungus, which genes? Development and assessment of universal primers for potential secondary fungal DNA barcodes. Persoonia 35:242-263.

Sung, G.-H., Sung, J.-M., Hywel-Jones, N. L., and Spatafora, J. W. 2007. A multigene phylogeny of Clavicipitaceae (Ascomycota, Fungi): Identification of localized incongruence using a combinational bootstrap approach. Mol. Phylogenet. Evol. 44:1204-1223.

Tajima, F. 1989. Statistical method for testing the neutral mutation hypothesis by DNA polymorphism. Genetics 123:585-595.

Tatarinova, T. V., Chekalin, E., Nikolsky, Y., Bruskin, S., Chebotarov, D., McNally, K. L., and Alexandrov, N. 2016. Nucleotide diversity analysis highlights functionally important genomic regions. Sci. Rep. 6:35730.
Templeton, A. R., Crandall, K. A., and Sing, C. F. 1992. A cladistics analysis of phenotypic associations with haplotypes inferred from restriction endo nuclease mapping and DNA sequence data III. Cladogram estimation. Genetics 132:619-633.

Thomma, B. P. H. J. 2003. Alternaria spp.: From general saprophyte to specific parasite. Mol. Plant Pathol. 4:225-236.

Ushijima, K., and Yamamoto, M. 2019. A sequence resource of autosomes and additional chromosomes in the peach pathotype of Alternaria alternata. Mol. Plant-Microbe Interact. 32:1273-1276.

Wan, J., Tanaka, K., Zhang, X. C., Son, G. H., Brechenmacher, L., Nguyen, T. H., and Stacey, G. 2012. LYK4, a lysin motif receptor-like kinase, is important for chitin signaling and plant innate immunity in Arabidopsis. Plant Physiol. 160: 396-406.

Wang, X., Jiang, N., Liu, J., Liu, W., and Wang, G. L. 2014. The role of effectors and host immunity in plant-necrotrophic fungal interactions. Virulence 5: 722-732.

White, T. J., Bruns, T., Lee, S., and Taylor, J. W. 1990. Amplification and direct sequencing of fungal ribosomal RNA genes for phylogenetics. Pages 315-322 in: PCR Protocols: A Guide to Methods and Applications. M. A. Innis, D. H Gelfand, J. J. Sninsky, and T. J. White, eds. Accademic Press Inc., San Diego, CA.

Wolf, J., O'Neill, N. R., Rogers, C. A., Muilenberg, M. L., and Ziska, L. H. 2010 Elevated atmospheric carbon dioxide concentrations amplify Alternaria alternata sporulation and total antigen production. Environ. Health Perspect. 118:1223-1228.

Woudenberg, J. H. C., Seidl, M. F., Groenewald, J. Z., de Vries, M., Stielow, J. B. Thomma, B. P. H. J., and Crous, P. W. 2015. Alternaria section Alternaria: Species, formae speciales or pathotypes? Stud. Mycol. 82:1-21.

Wu, W. S., Li, Y. L., and Wu, H. C. 2006. Seed-borne fungi of ornamental flower plants. Australas. Plant Pathol. 35:373-375.

Yamada, K., Yamaguchi, K., Shirakawa, T., Nakagami, H., Mine, A., Ishikawa, K., Fujiwara, M., Narusaka, M., Narusaka, Y., Ichimura, K., Kobayashi, Y., Matsui, H., Nomura, Y., Nomoto, M., Tada, Y., Fukao, Y., Fukamizo, T., Tsuda, K., Shirasu, K., Shibuya, N., and Kawasaki, T. 2016. The Arabidopsis CERK1-associated kinase PBL27 connects chitin perception to MAPK activation. EMBO J. 35:2468-2483.

Yang, N., Ma, G., Chen, K., and Wu, X. 2018. The population genetics of Alternaria tenuissima in four regions of China as determined by microsatellite markers obtained by transcriptome sequencing. Front. Microbiol. 9:2904.

Zhu, X. Q., and Xiao, C. L. 2015. Phylogenetic, morphological, and pathogenic characterization of Alternaria species associated with fruit rot of blueberry in California. Phytopathology 105:1555-1567. 